\title{
Geophysics in Near-Surface Investigations
}

\author{
Jadwiga A. Jarzyna et al.* \\ AGH University of Science and Technology, \\ Faculty of Geology Geophysics and Environmental Protection, Krakow, \\ Poland
}

\section{Introduction}

Environmental and engineering geophysics are new branches of geophysics that focus on data collection and an analysis of the present day environment. Noninvasive, nondestructive, and inexpensive geophysical technologies are now capable of providing detailed 3D and 4D representations of the subsurface. These advances in geophysical survey techniques have not only enhanced traditional applications, such as prospecting geophysics, but also made way for development of new methodologies in near surface investigations. Environmental and engineering geophysics includes mapping of shallow geological formations, prospecting for resources located in the near surface, monitoring aquifers, mapping anthropogenic effects on the environment, and surveying for civil engineering and archaeological projects. Environmental and engineering geophysics measures parameters such as salinity of subsurface fluids, levels of radioactivity, and other soil properties affected by industrial activity.

The increasing demand for sustainable development as well as community efforts to preserve and conserve the environment have fostered the development of engineering technologies that are more environmentally friendly than traditional geophysical tools. Newer techniques are often used to monitor and protect the environment, as well as evaluate geotechnical risks of various natural and human - made structures. The increasing number of these modern geophysical applications, and of professionals specializing in them, bear witness to their emerging significance.

\section{Petrophysical background for geophysical investigations (Jadwiga A. Jarzyna)}

Petrophysics is a subdiscipline of geophysics that addresses the physical properties and other parameters of rock and other subsurface material. Applied geophysics combines the theoretical foundation of a given geophysical method with empirical understanding of the materials involved. In the case of petrophysics, theoretical parameters of rock and other subsurface materials (i.e. their physical properties) are used to interpret empirical

\footnotetext{
* Jerzy Dec, Jerzy Karczewski, Sławomir Porzucek, Sylwia Tomecka-Suchoń, Anna Wojas and Jerzy Ziętek

AGH University of Science and Technology, Faculty of Geology Geophysics and Environmental Protection, Krakow, Poland
} 
observations (i.e. quantities, subsurface extent etc.). For example, geoeletrical investigations use Archie's law (theoretical) to interpret voltage and current measurements (empirical) to gain insight into the effective porosity and resistivity of the materials under study.

Petrophysics provides empirical information on rocks from laboratory measurements and field investigations. Laboratory measurements offer a direct way to determine rock parameters, but the results are not always directly applicable to the real world. The relatively small size of samples studied in typical laboratory experiments, and the complexity of the natural environment bedevil integration of laboratory results not just in applied geophysics, but in nearly all Earth science disciplines. High costs of drilling and limited number of cores can also constrain the practicality of investigations that rely heavily on parameters gathered through laboratory experiments.

In spite of these constraints, petrophysics aims to consistently integrate information from laboratory and field measurements. In subsurface investigations for example, the accuracy and resolution of geological profiles depend heavily on parameters provided by field measurements. Field measurements such as resistivity, measured by surface geoelectric methods and resistivity well logs, in turn reflect both the heterogeneity of subsurface rock formations and operational characteristics of the device used to perform the measurement. Given the variability among these factors, statistical methods can be used to synthesize and interpret data obtained using different methodologies. Empirical formulas generated through petrophysical investigations can also be used to standardize, calibrate and scale geophysical devices.

In practice, petrophysics often provides geophysical models with estimates of subsurface parameters. Estimated parameters can include bulk density, resistivity, dielectric permittivity, velocity of elastic waves, and magnetic susceptibility. In reservoir characterization for example, petrophysics parameterizes porosity, permeability and filtration factors. Accurate and consistent estimation of these parameters requires understanding of mineral composition, porosity, and properties of the interstitial media, (i.e. salinity, temperature, etc.). In larger scale studies of anisotropy, petrophysics provides estimates of structure, texture and facies type for materials under investigation.

Petrophysical analysis begins with the assumptions that the subsurface is heterogeneous and may undergo change. Subsurface materials may vary in terms of their geometry, size, composition, structure and other properties. Petrophysical and petrochemical variables address heterogeneity in these properties by averaging them over unit volumes. Subsurface materials are also affected by temperature, pressure and the resonant frequencies of physical fields used to evaluate them. Near surface investigations are less dependent on subsurface pressure and temperature conditions than traditional (deeper) geophysical applications, but these factors still come into play. Lack of compaction or varying degrees of consolidation in near surface materials can result in differing resistivity and bulk density for rocks of identical lithology, but occurring at different depths. Physical fields are also affected by consolidation and compaction. Loose subsurface sands and gravels, as well as sandstones and mudstones in the aeration zone have anomalously high resistivity for example, due to the air content of their pore space.

Because most of the near surface is composed of sediments and sedimentary rock, this chapter focuses on these materials. The chapter first outlines the basics of petrophysical 
properties, and then describes their use in environmental and engineering geophysical applications. The most basic petrophysical property of rock is that of density. Bulk density is defined as the ratio of a rock's mass to its volume. It is lower or equal to matrix density (mineralogical density, specific density), which is defined as the ratio of the mass of a rock in powdered form, to its volume. Bulk density of sedimentary rocks, $\delta_{b}$, depends on the density of minerals (matrix material), $\delta_{\mathrm{m}}$; porosity, $\Phi$; and density of the pore space media, $\delta_{\mathrm{f}}(2.1)$.

$$
\delta_{b}=(1-\Phi) \delta_{m}+\Phi \delta_{f}=\delta_{m}-\left(\delta_{m}-\delta_{f}\right) \Phi
$$

Bulk density is intuitively inversely proportional to porosity, but it is specifically a function of matrix and pore media density. For example, gaseous hydrocarbons in the pore space of a reservoir rock will significantly decrease its bulk density. Most rock-forming minerals have bulk densities ranging from 2200 to $3500 \mathrm{~kg} / \mathrm{m}^{3}$. Ore bodies and associated minerals have average densities of 4000 to $8000 \mathrm{~kg} / \mathrm{m}^{3}$. Sedimentary rocks are composed of matrix materials that range in average density from 2500 to $2900 \mathrm{~kg} / \mathrm{m}^{3}$, of fluids ranging from 800 to $1240 \mathrm{~kg} / \mathrm{m}^{3}$, and of gases that have average densities of less than $1000 \mathrm{~kg} / \mathrm{m}^{3}$ (Kobranova, 1989). Given variation in the densities of sedimentary components, the range in bulk density can be quite broad from lignite $\left(1000-1300 \mathrm{~kg} / \mathrm{m}^{3}\right)$; clay $\left(1300-2300 \mathrm{~kg} / \mathrm{m}^{3}\right)$; sand and gravel $\left(1400-2300 \mathrm{~kg} / \mathrm{m}^{3}\right)$; loam $\left(1500-2200 \mathrm{~kg} / \mathrm{m}^{3}\right)$; sandstone $\left(2000-2800 \mathrm{~kg} / \mathrm{m}^{3}\right)$; shale $\left(2300-2800 \mathrm{~kg} / \mathrm{m}^{3}\right)$; limestone $\left(2300-2900 \mathrm{~kg} / \mathrm{m}^{3}\right)$; and dolomite $\left(2400-2900 \mathrm{~kg} / \mathrm{m}^{3}\right)$; (Schön, 2004). Porosity is an important property of sedimentary rocks that often enters into petrophysical considerations. Total porosity is defined as the volume of free space per given volume of rock. Effective porosity refers only to the volume of connected pores, fractures, fissures and vugs. Porosity can be modelled as spherical volumes of various radii (Kobranova, 1989) but is more reliably measured in the laboratory using rock samples or well $\log$ data. Porosity is related to texture, mineral composition, sedimentary fabric and

a)

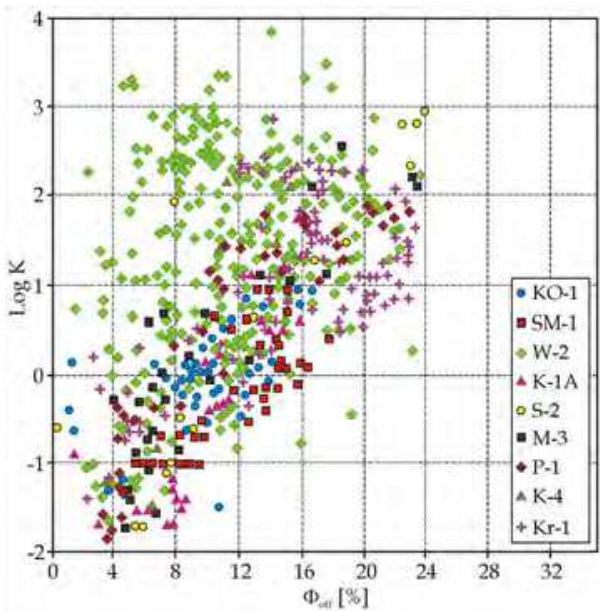

b

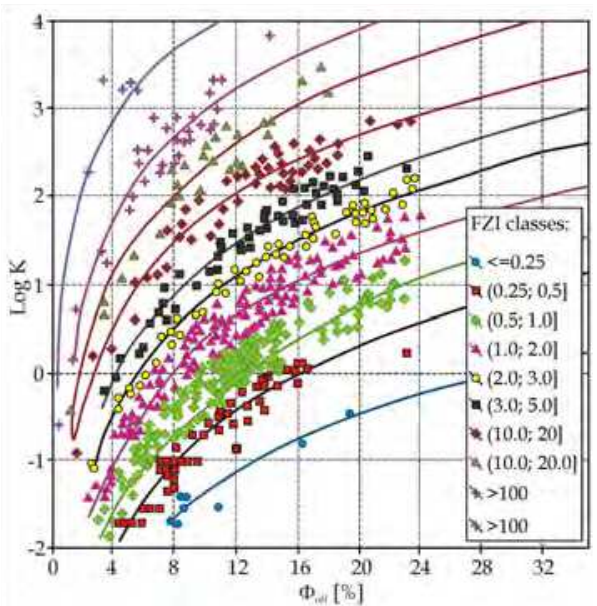

Fig. 2.1 Permeability vs. porosity of the Rotliegend sandstones; a) datasets from different wells; b) datasets ordered according FZI (Jarzyna et al., 2009). 
degree of lithification. Clay content reduces porosity. Permeability is the ability of a material to transmit pore media, which depends heavily on the material's porosity. A functional alternative to calculating a rock's hydraulic properties as separate porosity and permeability variables is the Flow Zone Index (FZI). FZI depends on permeability and porosity, specifically considers tortuosity of pore space and specific surfaces without parameterizing either of these quantities. The advantages of using FZI over porosity and permeability are presented in figure 2.1 (Tiab \& Donaldson, 2004; Jarzyna et al., 2009).

Resistivity and dielectric permittivity refer to electric properties of rocks. Both properties depend on mineral composition, porosity and properties of the pore space media. Dielectric permittivity is inversely proportional to the electromagnetic (EM) field frequencies often used in geophysical measurements. Factors such as water saturation may also influence the dielectric permittivity of subsurface materials. Frequency dependence makes it a dispersive parameter. Because the dielectric permittivity of water is relatively high compared to permittivity values for minerals and hydrocarbons, this parameter can be used to distinguish hydrocarbon plumes in water saturated materials. In terms of resistivity, silicates and carbonates have high specific resistivities (>109 Ohmm; Kobranova, 1989) and are thus classified as insulators. Sulfides and some oxides meanwhile are classified as mineral conductors (specific resistivities between $10^{-6}$ and $10^{-1} \mathrm{Ohmm}$ ), as are native metals $\left(10^{-8}\right.$ to $\left.10^{-5} \mathrm{Ohmm}\right)$. Variation in the specific resistivities of various minerals can be due to the presence of impurities, subsurface structural effects, and anisotropy. Relative dielectric permittivity, $\varepsilon_{\mathrm{r}}$, is defined as the dielectric permittivity of rock, $\varepsilon$, divided by the dielectric permittivity of vacuum, $\varepsilon_{0}$. For most rock forming minerals, $\varepsilon_{\mathrm{r}}$ ranges between 4 and 10 (Table 2.1). Relative dielectric permittivity is correlated to bulk density (2.2). The generalized formula (2.2) applies to most minerals with the exception of hydrated forms of montmorillonite and members of the sulfide group (Schön, 2004).

$$
\varepsilon_{r}=(1.93 \pm 0.17)^{\delta_{b}}
$$

\begin{tabular}{|c|c|c|c|c|c|c|c|c|}
\hline Mineral & $\begin{array}{c}{ }^{*} \mathrm{~V}_{\mathrm{P}} \\
{[\mathrm{km} / \mathrm{s}]}\end{array}$ & $\begin{array}{c}{ }^{*} \mathrm{~V}_{\mathrm{S}} \\
{[\mathrm{km} / \mathrm{s}]}\end{array}$ & $\begin{array}{c}{ }^{*} \delta_{\mathrm{b}} \\
{\left[\mathrm{kg} / \mathrm{m}^{3}\right]}\end{array}$ & $\begin{array}{c}{ }^{*} \varepsilon_{\mathrm{r}} \\
{[\mathrm{MHz}]}\end{array}$ & Rock & $\begin{array}{c}\mathrm{V}_{\mathrm{P}} \\
{[\mathrm{km} / \mathrm{s}]}\end{array}$ & $\begin{array}{c}\mathrm{E} \\
{[\mathrm{GPa}]}\end{array}$ & $\sigma$ \\
\hline Quartz & 5.492 & 4.119 & 2650 & & Sandstone $^{\wedge}$ & $0.8-4.5$ & $30-100$ & $0.06-0.6$ \\
\hline Calcite & 6.403 & 3.436 & 2710 & $6.35 ; 7.5-8.7$ & Sandstone $^{\#}$ & $1.4-4.3$ & $3-41$ & $0.13-0.33$ \\
\hline Orthoclase & 5.690 & 3.260 & 2570 & $5.6 ; 4.5-6.2$ & Sandy shale $^{\wedge}$ & $1.45-5.18$ & $5-69$ & $0.12-0.21$ \\
\hline Dolomite & 7.007 & 4.293 & 2870 & $7.46 ; 6.3-8.2$ & ${\text { Sand }(\text { dry })^{\#}}^{*}$ & $0.2-1.0$ & $0.03-0.72$ & 0.405 \\
\hline Anhydrite & 6.096 & 3.126 & 2960 & $6.5 ; 5.7-6.7$ & ${\text { Sand }(\text { wet })^{\#}}^{*}$ & $0.8-2.2$ & $0.55-4.18$ & 0.405 \\
\hline Siderite & 6.959 & 3.590 & 3960 & $9.3 ; 5.2-7.4$ & Clay $^{\wedge}$ & $0.3-3$ & 30 & $0.25-0.45$ \\
\hline Pyrite & 8.021 & 5.166 & 5020 & $33.7-81$ & Clay $^{\#}$ & $1.0-2.5$ & $0.78-4.91$ & 0.405 \\
\hline Hematite & 6.626 & 4.233 & 5270 & 25 & Shale $\left(\right.$ slate $^{\wedge}$ & $2.3-6.65$ & $24-72$ & 0.17 \\
\hline Magnetite & 4.175 & 1.966 & 5180 & $33.7-81$ & Limestone $^{\wedge}$ & $1.0-7.0$ & $13-175$ & $0.18-0.31$ \\
\hline Kaolinite & 1.438 & 0.929 & 2610 & $11.8 ; 9.1$ & Limestone $^{\#}$ & $5.9-6.1$ & $55-63$ & $0.34-0.354$ \\
\hline Biotite & 6.220 & 3.717 & 3010 & $6.3 ; 6.2-9.3$ & Marl $^{\wedge}$ & $1.3-4.5$ & $10-135$ & $0.11-0.23$ \\
\hline Halite & 4.549 & 2.628 & 2170 & $5.9 ; 5.7-6.2$ & Granite $^{\#}$ & $5.5-5.9$ & $56-64$ & 0.325 \\
\hline
\end{tabular}

Table 2.1 Petrophysical properties of minerals and rocks (*after Halliburton, 1991; ** Schön, 2004; ^Kobranova, 1989; \#calculated on the basis of averaged data). 
The specific resistivity of air equals $10^{14} \mathrm{Ohmm}$, and is similar to that of hydrocarbons. Electrolytes are ionic conductors. Conductivity of porous, fractured rocks is caused by ionic movement in subsurface fluids. Under these conditions, resistivity depends primarily on mineral type, rock fabric, temperature of the subsurface fluid, and the volume of connected pores. The resistivity of pure water (containing only $\mathrm{H}^{+}$and $\mathrm{OH}^{-}$ions) is very high ( $>10^{5}$ Ohms; Hearst et al., 2000). Conductivity, $\sigma_{w}$, and resistivity of subsurface water $\left(\rho_{\mathrm{w}}\right)$, depends on several factors $(2.3 ; 2.4)$ :

$$
\begin{gathered}
\sigma_{w}=\frac{1}{\rho_{w}} \cong \sum_{i=1}^{n} \alpha_{i} c_{i} z_{i} v_{i} \\
\rho_{w}\left(t_{2}\right)=\rho_{w}\left(t_{1}\right) \frac{t_{1}+21.5}{t_{2}+21.5}
\end{gathered}
$$

In equations 2.3 and $2.4, \mathrm{n}$ is the number of components in the subsurface water, $\alpha$ is the degree of dissociation, $\mathrm{c}$ is the concentration, $\mathrm{z}$ is the valence, and $\mathrm{v}$ is the mobility. Factors of $a$ and $v$ depend on temperature. Models often assume that pore fluid is a simple sodiumchloride solution. Formula 2.4 shows that pore fluid resistivity is temperature dependent. The variables $t_{1}, t_{2}$ are temperatures given in Celsius degrees. The relative dielectric permittivity of pore water, $\varepsilon_{\mathrm{r}}=81\left(\mathrm{at} \mathrm{t}=21^{\circ} \mathrm{C}\right)$ differs from that of oil and gas $\left(\varepsilon_{\mathrm{r}}<3\right)$. Salt concentration, $\mathrm{c}_{\mathrm{mol}}$ (given in moles per liter), exerts a relatively small influence on the relative dielectric permittivity of pore fluids. The relative dialectric permittivity of pore fluids, $\varepsilon_{\mathrm{r}}$, is related to $\mathrm{c}_{\mathrm{mol}}$ as follows (Schön, 2004):

$$
\varepsilon_{r}=\varepsilon_{r_{-} \text {pure_water }}-13 \cdot c_{\text {mol }}+1.065 \cdot c^{2}{ }_{m o l}-0.03006 \cdot c^{3}{ }_{m o l}
$$

Dielectric permittivity, $\varepsilon_{\mathrm{r}}$, the velocity of electromagnetic waves, $\mathrm{V}_{\mathrm{EM}}$, and EM attenuation, $\mathrm{A}_{\mathrm{EM}}$, are used in georadar investigations. The dielectric permittivity of porous rocks strongly depends on the degree of water saturation. The salinity of pore water does not strongly affect $\varepsilon_{\mathrm{r}}$ (2.5), but does influence conductivity and attenuation of electromagnetic waves. Selected values for the electromagnetic properties of different pore media as well as surface and subsurface materials are presented below in Table 2.2.

\begin{tabular}{|c|c|c|c|c|c|c|c|c|c|}
\hline Material & $\begin{array}{c}\text { etha- } \\
\text { nol }\end{array}$ & $\begin{array}{c}\text { glyce- } \\
\text { rine }\end{array}$ & oil & $\begin{array}{c}\text { petro- } \\
\text { leum }\end{array}$ & ice & $\begin{array}{c}\text { ice } \\
*\end{array}$ & $\begin{array}{c}\text { ice } \\
* *\end{array}$ & $\begin{array}{c}\text { snow } \\
\wedge\end{array}$ & $\begin{array}{c}\text { snow } \\
\wedge \wedge\end{array}$ \\
\hline$\varepsilon_{\mathrm{r}}$ & 25.8 & 56.2 & $2.0-2.7$ & $2.0-2.2$ & 3.1 & 4,15 & 3.2 & 1.2 & 1.55 \\
\hline Material & $\begin{array}{c}\text { water } \\
\text { (fresh) }\end{array}$ & $\begin{array}{c}\text { water } \\
(\text { saline })\end{array}$ & $\begin{array}{c}\text { ice } \\
\#\end{array}$ & $\begin{array}{c}\text { silts } \\
\#\end{array}$ & $\begin{array}{c}\text { sand } \\
\text { (dry) }\end{array}$ & $\begin{array}{c}\text { sand } \\
\text { (wet) }\end{array}$ & air & clay & peat \\
\hline$\varepsilon_{\mathrm{r}}$ & 80 & 80 & $3-4$ & $5-30$ & 4 & 25 & 1 & $5-40$ & $60-80$ \\
\hline $\mathrm{V}_{\mathrm{EM}}[\mathrm{m} / \mathrm{ns}]$ & 0.03 & 0.03 & 0.16 & 0.07 & 0.15 & 0.06 & 0.30 & $0.05-0.13$ & $0.03-0.04$ \\
\hline $\mathrm{A}_{\mathrm{EM}}[\mathrm{dB} / \mathrm{m}]$ & 0.1 & 1000 & 0.01 & $1-100$ & 0.01 & $0.03-0.3$ & 0 & $1-300$ & 0.3 \\
\hline
\end{tabular}

Table 2.2 Relative dielectric permittivity of selected materials; *from pure distilled water $\left(-12^{\circ} \mathrm{C}, 10^{6} \mathrm{~Hz}\right){ }^{* *}$ from pure distilled water $\left(-12^{\circ} \mathrm{C}, 10^{9} \mathrm{~Hz}\right), \wedge$ freshly fallen, hard packed, followed by rain $\left(-20^{\circ} \mathrm{C}, 10^{6}-10^{9} \mathrm{~Hz}\right), \wedge \wedge$ freshly fallen, hard packed, followed by rain $\left(-6^{\circ} \mathrm{C}\right.$, $10^{6} \mathrm{~Hz}$ ) (after Schön, 2004; \# from http://www.physics.utoronto.ca/ exploration/courses). 
For rocks that have no clay minerals, Archie's laws (2.6 and 2.7) describe the relationships among the resistivity of fully saturated rock $\left(R_{0}\right)$, the resistivity of rock partially saturated with water and hydrocarbons $\left(R_{t}\right)$, effective porosity $\left(\Phi_{\text {eff }}\right)$, resistivity of formation water $\left(R_{w}\right)$, and water saturation $\left(S_{w}\right)$ or hydrocarbon saturation $\left(1-S_{w}\right)$. Relationship I vs. $S_{w}(2.7$; Archie law) may be nonlinear on a bi-logarithmic scale, especially if there are several different brine or porosity systems within the subsurface formation, or if the formation has a significant fine-grained lithological component ( $\leq$ mud sized particles).

$$
\begin{gathered}
F=\frac{R_{0}}{R_{w}}=\frac{1}{\Phi_{e f}{ }^{m}} \\
I=\frac{R_{t}}{R_{0}}=\frac{1}{S_{w}{ }^{n}}
\end{gathered}
$$

In equations 2.6 and $2.7, \mathrm{~F}$ is the formation factor, $\mathrm{I}$ is the resistivity index, $\mathrm{m}$ is a cementation factor ranging from 1.3 for unconsolidated sediments, to 2.2 for lithified, nonporous, non-permeable rock, and $\mathrm{n}$ is the saturation exponent, ranging from 1.12 to 2.55 for sandstone, and from 1.1 to 2.38 for limestone. The variables $\mathrm{m}$ and $\mathrm{n}$ are empirically determined (Tiab \& Donaldson, 2004).

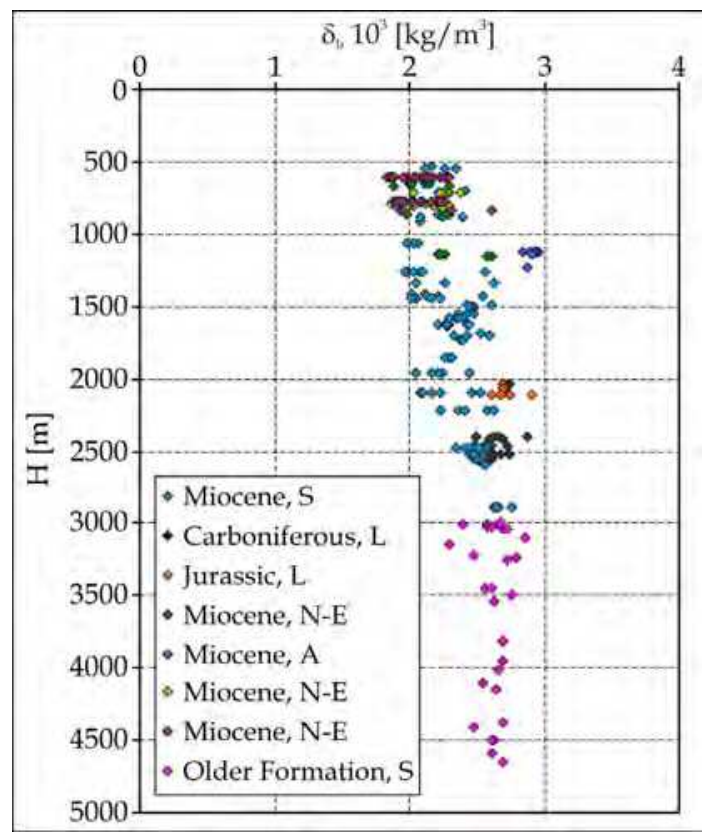

Fig. 2.2 Bulk density vs. depth; sandstone, S, limestone, L, anhydrite, A, Miocene N-E north-eastern Carpathian Foredeep. 


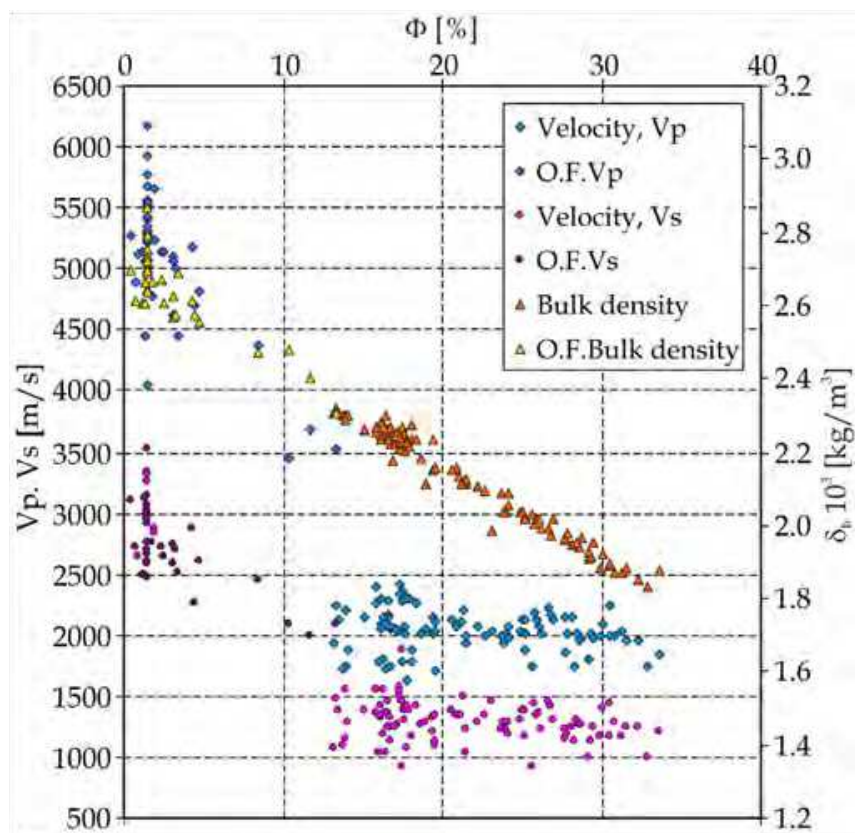

Fig. 2.3 Velocity and bulk density vs. porosity; Miocene sandstones and anhydrites; O.F.- units older than Permian.

Velocities of elastic waves used in seismic surveys (longitudinal P-waves, and shear S-waves) strongly depend on porosity and elastic moduli of the subsurface matrix, and on the type and properties of the pore space media. P- and S-wave velocities, along with bulk density and lithological information are used to calibrate seismic profiles. The velocity ratio, $\mathrm{V}_{\mathrm{P}} / \mathrm{V}_{\mathrm{S}}$, and acoustic impedance can indicate differences in lithology. Many petrophysical parameters are strongly depth dependent, and wave velocities in particular can be obscured by depth dependent changes in materials (Fig. 2.2). Porosity typically reduces velocity (Fig. 2.3.), as described by the Wyllie equation, the Raymer-HuntGardner formula, and by others (Schön, 2004). A velocity correction for lack of compaction is necessary for empirical analysis of unconsolidated near-surface materials. Clays lower the elastic moduli of rocks and thus significantly reduce velocities of elastic waves. Velocities in clay-rich materials are lower than those in quartz- or calcite- rich materials (Table 2.1) while the compressibility of clay is higher than that of quartz and calcite. Clay properties are also strongly influenced by water volume. The above factors lead to complex relationships among the physical properties of subsurface materials that have high clay and water content.

Wave velocities in frozen unconsolidated sediments (permafrost) are similar to velocities in consolidated sediments, as ice can serve as a cement. Pronounced differences in the $V_{P} / V_{S}$ ratio for gas- and water-saturated rocks are useful in energy exploration and cases of subsurface hydrocarbon contamination. Differences in the $V_{P} / V_{S}$ ratio for gas and liquid saturated materials arise from the differential influence of pore space media on P- and $S$-wave velocities (differing effects on $V_{P}$ and $V_{S}$, respectively). Velocities (for Poisson ratio, 
o) and bulk density (for Young modulus, E, and others) can be used to calculate the dynamic elastic moduli of rocks. Sonic well logs record full, acoustic waveforms for in situ elastic wave velocity analysis. In unconsolidated, near-surface sediments, shear wave velocity can be lower than the velocity of borehole mud. Under these conditions, it is necessary to use a formula derived from the Stoneley wave equation in order to calculate S-wave velocity (Jarzyna et al., 2010). Sedimentary rocks are often anisotropic and well layered. When

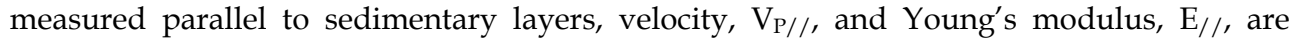
greater than $\mathrm{V}_{\mathrm{P}} \perp$ and $\mathrm{E}^{\perp}$, measured perpendicular to layers. The anisotropic coefficient of longitudinal wave velocity can reach values of 1.2 to 1.3. These values can exceed transverse wave coefficients and anisotropic coefficients pertaining to Young's modulus ( 1.1 to 2.0; Kobranova, 1989). In finely laminated rocks, such as shale-rich sandstones, elastic waves having wavelengths longer than the thickness of the individual laminae must be normalized in order to calculate the effective properties of the material.

Magnetic susceptibility is an important parameter for soils and shallow subsurface rocks containing ferrimagnetic minerals. The magnetic susceptibility of soil and rock depends on shape, size and concentration of susceptible minerals. Most minerals are dia- and paramagnetic. Antiferrimagnetic minerals are relatively rare and ferromagnetic minerals are very rare (Kobranova, 1989). Specific volumetric susceptibility, $\mathrm{K}$, and mass susceptibility, $X$, respectively, are proportionality coefficients in the presented below mutual relationships:

$$
\begin{aligned}
& \vec{J}_{v}=\kappa \cdot \vec{H} \\
& \vec{J}_{m}=\chi \cdot \vec{H} \\
& \chi=\kappa / \delta_{m}
\end{aligned}
$$

In equations 2.8 and 2.9, $\vec{H}$ is magnetic field, $\vec{J}_{v}$ is specific volume, and $\vec{J}_{m}$ is specific mass magnetization.

The magnetic susceptibility of dia- and paramagnetic native elements is governed by their chemical properties. For multi-element minerals, magnetic susceptibility is governed by stoichiometric composition and the arrangement of elements in the crystal lattice. The specific volumetric magnetic susceptibility of diamagnetic minerals is negligible and negative in value, ranging from -5.024 to $-1.63 \times 10^{-4}$ SI units (Kobranova, 1989). The most common minerals found in sedimentary rocks are diamagnetic (i.e. quartz, calcite, feldspar, dolomite, gypsum, halite, etc). Trace minerals such as biotite, pyrite, ilmenite, siderite, chlorite, and clays are paramagnetic or paraferrimagnetic. Accessory minerals such as magnetite, maghemite, hematite, and goethite are ferro- or ferrimagnetic. Magnetite is one of the most susceptible minerals, with 1.25 to 25 or more SI units. Water and oil are diamagnetic $\left(\kappa_{w}=\chi_{w}=-0.910^{-5}\right.$ and $\kappa_{0}=\chi_{0}=-1.0410^{-5}$ SI units, respectively). The influence of the mineral matrix on the susceptibility of the pore fluid is insignificant. Gases, including gaseous hydrocarbons have much lower magnetic susceptibility than liquids. Oxygen is paramagnetic with a relatively low, $\mathrm{K}_{\text {oxyg }}=0.17 \times 10^{-5}$ SI units. The magnetic susceptibility of air, $\mathrm{K}_{\mathrm{air}}$, equals $0.04 \times 10^{-5} \mathrm{SI}$ units. The ferromagnetic properties of magnetized rocks are the basis of magnetic surveys, paleogeographic reconstructions, and the paleomagnetic record. 
Iron-oxide minerals are often used as paleoenvironmental proxies due to their high magnetic susceptibility, and because environmental conditions can be interpreted from iron oxide composition and grain size distribution.

\section{Near surface georadar investigations (Jerzy Karczewski \& Jerzy Ziętek)}

In recent years, ground penetrating radar (GPR) has become the most popular geophysical method for near surface investigations. GPR belongs to a group of radio wave methods which evaluate electromagnetic wave propagation within a geological medium. The most popular GPR apparatus is the impulse type, which uses transmitting antennas to emit short electromagnetic pulses of 0.5 to $10 \mathrm{~ns}$ in the $10 \mathrm{MHz}$ to $6 \mathrm{GHz}$ frequency range (f). Under favorable conditions, low frequency antennas ( $<<50 \mathrm{MHz}$ ) can be used to map the structure of the subsurface down to depths of a few dozen meters. Higher frequency pulses increase the resolution of shallow features, but decrease the depth range of the survey. EM waves from GPR devices can be attenuated, reflected or refracted. Reflection or refraction coefficients of EM waves for a given subsurface boundary layer will depend on different dielectric permittivities $(\varepsilon)$ of the materials involved. Dielectric permittivity also influences velocities of the EM waves. Wave attenuation depends on wave frequency and the conductivity of the media, which in turn is strongly influenced by depth. While GPR devices are cheap and relatively easy to operate, GPR echograms are difficult to interpret and require knowledge of subsurface structure and petrophysical properties. Methods for processing GPR field data can enhance signal to noise ratios and the accuracy of reflector images. The most common GPR processing procedures include DC-Bias, time gain, filtration in the frequency domain, $\mathrm{f} / \mathrm{k}$ filtration, deconvolution, migration and others (Annan, 2001; Daniels, 2004; Jol, 2009).

\subsection{Landslide investigations}

Landslides can damage infrastructure and pose a variety of other environmental risks. Mass wasting during a landslide event strongly depends on topography, hydrology, the structure of underlying bedrock, soil and bedrock type, and other factors. Strategies for landslide risk mitigation require a detailed understanding of the internal structure of the landslides, especially the slide surface. GPR surveys performed to image a landslide surface should profile the main landslide axis, as well as an axis perpendicular to the slide if possible.

For landslides that cut through inclined layers, a topographic correction is necessary to properly locate and map the slide surface. Stacking of multiple signals during data acquisition and maximizing the number stacked signals improves the significance and clarity of the echograms. If the terrain permits, several parallel profiles can be recorded to render a 3D map of the main slide surface. A small landside that destroyed a relatively new house in the south of Poland provides a case study of the methods described above. GPR was used to locate and map the landslide surface, which developed following a period of heavy rain in 1997 (Fig. 3.1). No landslide activity had been observed in the area prior to 1997, leading investigators to suspect that construction of the house and it adjacent swimming pool in 1995 may have disturbed the geotechnical balance of the property. Later drilling revealed the lithological composition of the subsurface rocks, and confirmed the presence of slide surface. 


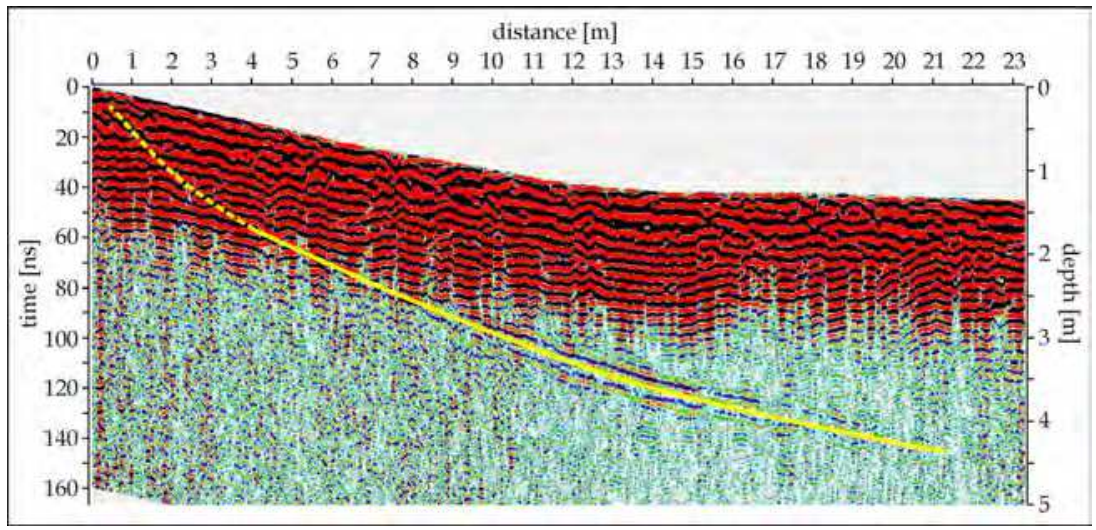

Fig. 3.1 GPR echogram of a landslide. RAMAC/GPR apparatus, $200 \mathrm{MHz}$ antennas.

\subsection{GPR in archeology}

More and more archeological investigations utilize geophysical methods of magnetometry, GPR, and geoelectrics. Features such as old moats, ramparts, walls, basements, cemeteries, residual strongholds, foundations, and tumuli have all been located using GPR methods. Archeological objects can be successfully identified using medium frequency antennas, as they are buried at depths of less than $10 \mathrm{~m}$. GPR is non-invasive and thus offers the advantages of speed and precision in archeology, as well as the possibility of object recognition without digging an exploratory trench. Archeological interpretations can be optimized by doing GPR profiles of an entire grid system if terrain conditions permit. Under these conditions a GPR survey can significantly reduce the time and effort necessary to locate subsurface objects, thus lowering the costs of excavation. GPR can also help optimize design of research trenches and excavation plans for specific objects. Higher frequency GPR records can help differentiate small artifacts from other, less significant fragments of rock in the subsurface.

GPR is an especially effective, low impact method for surveys carried out inside historic buildings. Void space such as crypts, basements and tunnels can be detected as a large increase in EM wave velocity. As a result, the boundaries of void spaces are visible in echograms at apparent depths that are below the actual boundaries or floors of these features. Voids appear in echograms as low frequency impulses zones. Shielded antennas are often used for GPR measurements inside of buildings to reduce feedback from walls, ceilings and other objects (i.e. reflex anomalies), but unshielded antennas can also provide adequate results. Echograms collected inside buildings can contain a significant amount of noise from reflex anomalies, but these datasets have nevertheless facilitated numerous archeological discoveries.

GPR surveys of Saint Margaret's collegiate in central Poland for example, were used to determine whether a Romanesque basement excavated outside of the church continued beneath the floor of the historic structure above. A GPR survey using shielded antennas (800 $\mathrm{MHz}$ ) confirmed that the basement extended beneath the church (Fig. 3.2). Due to the architectural continuity of many historical structures, archeological GPR profiles can be 
planned according to known subsurface patterns, or the layout of the overlying structure. GPR surveys of the churches of Saint Peter and Saint Paul in Krakow were planned using the surface structure as a template (Fig. 3.3). In this example, the survey used shielded 250 $\mathrm{MHz}$ antennas and followed an aisle in the church that lay above known and accessible crypts. The longitudinal axes of the last two crypts (Fig. 3.3) are parallel to the profile. The echogram from the aisle was then used to interpret depth profiles of the nave of the church where unknown and inaccessible crypts were suspected to exist.

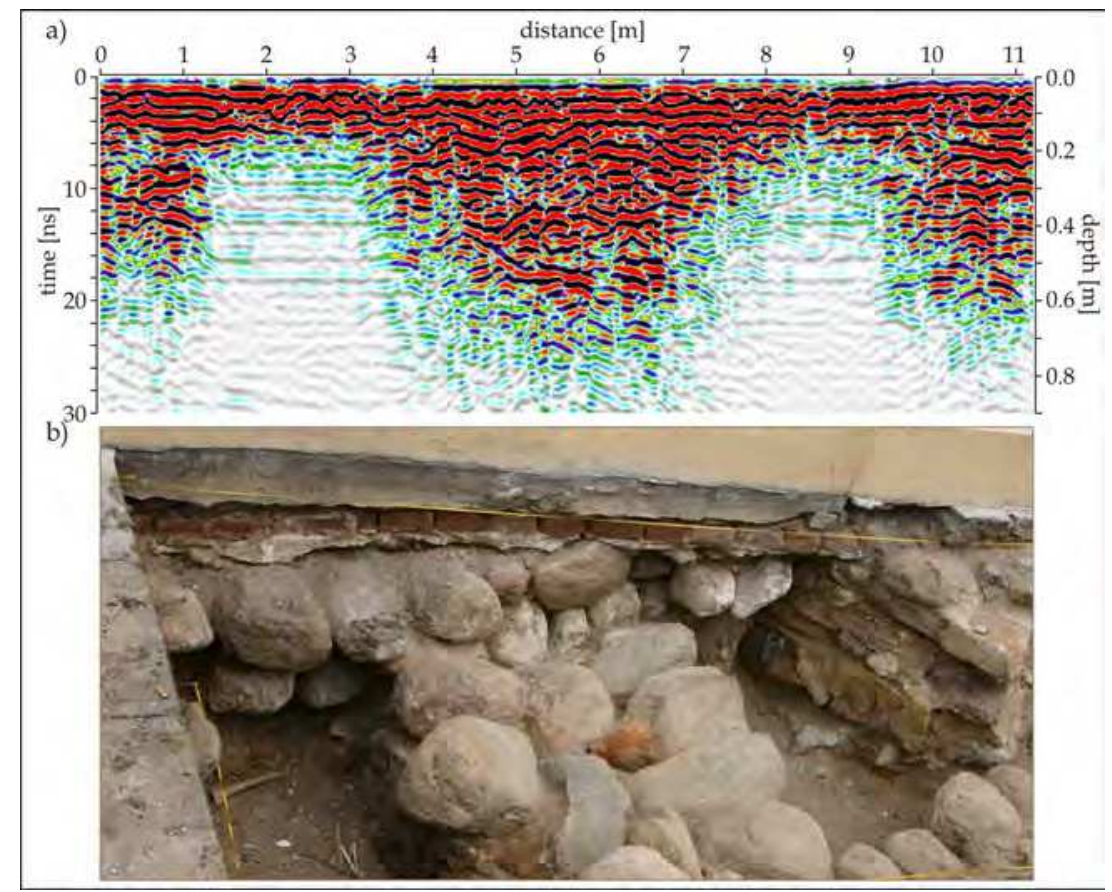

Fig. 3.2 GPR of Saint Margaret's collegiate in central Poland; a) echogram, b) ruins of the Romanesque basement. RAMAC/GPR apparatus, $800 \mathrm{MHz}$ antennas.

\subsection{GPR for controlling embankments}

River embankments, levies and dams that secure reservoirs, holding ponds and other bodies of water, require periodic maintenance and upgrade. Even robustly constructed embankments degrade over time, usually from infiltration at the embankment's base. Water filtration across the body of the embankment results in soil suffusion and liquefaction.

Animal burrows, vegetation, and other biological modifications can also degrade embankments. Assessment of embankments is usually performed using geotechnical methods. These include drilling wells, conducting well tests, testing of well plugs in the laboratory, and in situ ground testing. Geomorphological factors affecting embankments can be ascertained via larger scale surveys of the area, using maps, photointerpretation, photogrammetry. 


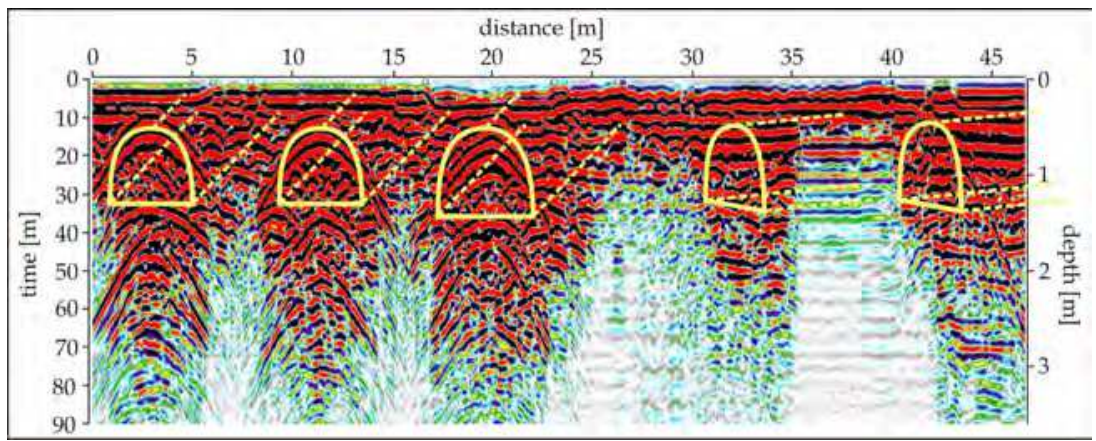

Fig. 3.3 Echogram in the Saint Peter and Saint Paul church in Krakow. RAMAC/CU II apparatus, shielded $250 \mathrm{MHz}$ antennas.

GPR is highly effective in locating zones of weakness in river embankments. This method is useful for performing qualitative investigations of the embankment's inner structure and basal materials. GPR measurement profiles are best carried out along the rim of an embankment, along inner and outer shelves, and also within intervening areas between the river and the embankment. GPR signals can render the subsurface in sufficiently high resolution as to show relatively small anomalies in the embankment's subsurface structure. Varying degrees of cementation for example can be detected by GPR. Lower frequency antennas are generally used to query an embankment's basal structure.

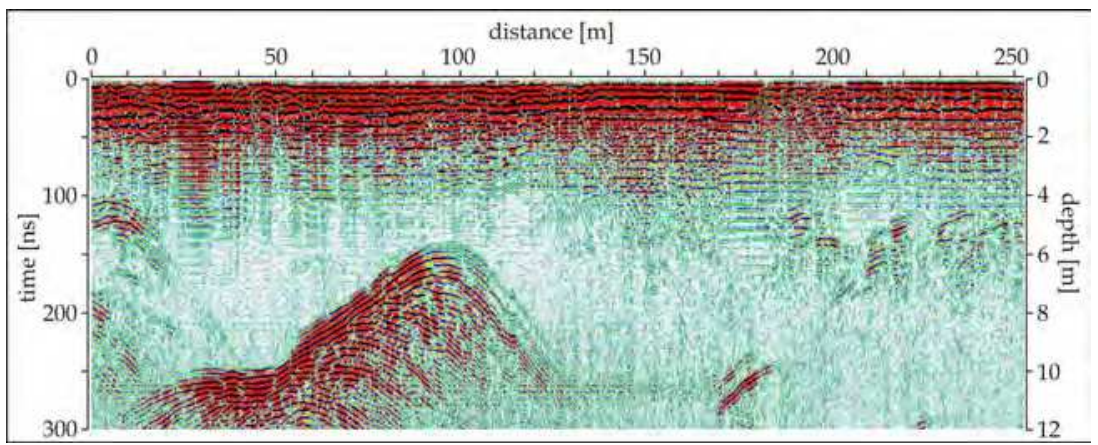

Fig. 3.4 Echogram of the Odra river embankment. RAMAC/GPR apparatus, unshielded $200 \mathrm{MHz}$ antennas.

Frequently, river embankments are composed of impermeable clays and silts, materials that have relatively low resistivity. These materials attenuate EM signals, allowing GPR surveys to penetrate only the shallowest zones of the subsurface. GPR signals can also be obscured by high water, flooding, or heavy rains which saturate embankment material, and thus attenuate EM waves (Nguyen et al., 2005). Trees growing on or near the embankment can also interfere with signals, obscuring recognition of heterogeneities.

In spite of these limitations, the high measurement efficiency and low cost of GPR relative to other methods recommend it as a first order survey strategy for assessing embankments. GPR anomalies can then be confirmed with second order geotechnical methods. Used in this 
way, GPR can optimize the more expensive assessment techniques, limiting their use to zones where GPR anomalies are apparent. The echogram shown in Fig. 3.4 was recorded on the Odra river embankment using $200 \mathrm{MHz}$ unshielded antennas. The height of the embankment along the section analyzed was about $4 \mathrm{~m}$. The goal of the investigation was to identify heterogeneities within the embankment and its basal materials. No meaningful heterogeneities were observed within the embankment but a significant anomaly appeared at its base. Drilling revealed that the anomaly was a permeable layer of coarse-grained gravel. Further study of the anomaly identified this area of the embankment as being at risk of hydraulic puncture during high water events.

\section{Georadar for monitoring soil contamination (Sylwia Tomecka-Suchoń)}

Georadar methods (GPR) are a valuable tool in detection and remediation of soil pollution due to their sensitivity to the electrical properties of subsurface materials. Hydrocarbons and salts leaking from containment at industrial sites are the two most common classes of soil pollutants. Hydrocarbon contamination is usually a consequence of leakage from collecting tanks and pipelines used in various petroleum operations. Mining operations with their sizeable holding ponds, debris, and chemical dumps can also pollute soil and ground water. Identification and remediation of hazardous chemicals is complicated by the fact that waste material can be distributed at various depths, and may migrate in any direction, at any speed. The GPR method is a particularly sensitive method under conditions of pore water saturation, due to the high relative dielectric permittivity of water. In saturated soils for example, GPR can be used to perform real time monitoring of contaminant plume migration. As with applications described in the previous section, GPR is non-invasive and allows parties involved to forgo the more expensive activities of digging wells and trenches (Gołębiowski et al., 2010a). Two case studies of GPR use in soil contamination studies are described below. These include both types of liquid pollutants: low-conductivity hydrocarbons (a fuel station in Krakow) and high-conductivity chemical solutions (former military installation at B-S (Poland), and D waste dump).

\subsection{Low-conductivity hydrocarbon contamination}

The conductivity of soil media depends on 1) the relative volumes of the components (e.g., articles, water, air) and 2) their conductivity. The former volumetric factors will in turn affect the soil's overall dielectric permittivity. Owing to its very high dielectric permittivity, $\left(\varepsilon_{\mathrm{r}}=81\right)$ water content greatly facilitates imaging of Light Non-Aqueous Phase Liquid (LNAPL) contamination in sandy subsurface materials. Hydrocarbons have a low $\varepsilon_{\mathrm{r}}$ (Table 2.1). Detection of a LNAPL plume in dry, aerated soil horizons is difficult, but in water saturated soils, phase separation occurs between the LNAPL plume and uncontaminated surroundings. Differences in permittivity mean that higher concentrations of immiscible hydrocarbons (e.g. gasoline) can enhance detection and mapping of plumes. LNAPL plumes tend migrate in a downward direction due to gravity and capillary action. When a plume reaches the capillary fringe zone, contrasting electromagnetic properties between contaminants and the surrounding medium resolve the plume in GPR echograms.

A GPR survey was carried out at a fuel station in Krakow (Gołębiowski et al., 2010a). The study area was contaminated by repeated spills where hydrocarbon mixtures soaked and infiltrated the ground surface. GPR measurements were carried out in a constant-offset 
reflection mode along two lines that transected the site. A RAMAC/GPR device was used with $200 \mathrm{MHz}$ antennas. Traces were collected every $0.05 \mathrm{~m}$ to generate a total of 64 stacked signals. All echograms were processed with the ReflexW program using phase correlation, time zero correction, amplitude declipping, dewowing, DC-shift, background removal, gain, the Butterworth filter, and smoothing procedures. Identification of contaminated zones was based on energy distribution analysis, counted from Hilbert transformation of raw signals. Areas where pockets of high energy (Fig. 4.1) overlapped anomalies in power spectra were interpreted as contaminated zones (Fig. 4.2). The energy envelope was normalized to the maximum value of the direct air wave.

Analysis of well cores (Fig. 4.1) found neither anisotropy nor other compositional anomalies in the subsurface of the study area. Parts of high energy in the echograms (violet area between $1 \mathrm{~m}$ and $2.5 \mathrm{~m}$ in Fig. 4.1) were therefore interpreted as contaminated zones. Analysis of GPR power spectra from the profile (Fig. 4.2) showed phase shifts and other irregularities that likewise indicated high concentrations of hydrocarbons. Power spectra irregularities correlated well with the zones of high energy in areas located at 15 and $32 \mathrm{~m}$ along the transect (Figs 4.1 and 4.2). The location of a high energy zone at $\sim 2.5 \mathrm{~m}$ depth highlighted depression or downward bowing of the water table due to the gravitational pressure of the hydrocarbon plume.

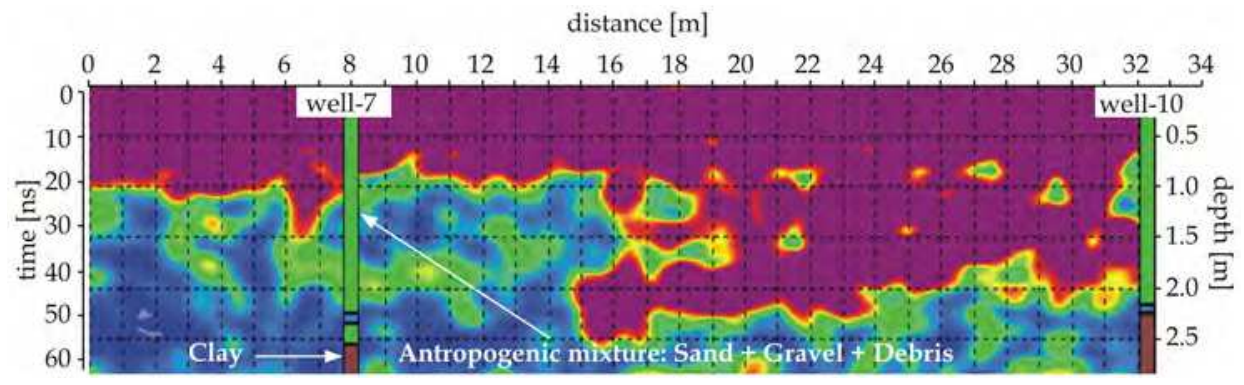

Fig. 4.1 GPR energy distribution (Gołębiowski et al., 2010a)

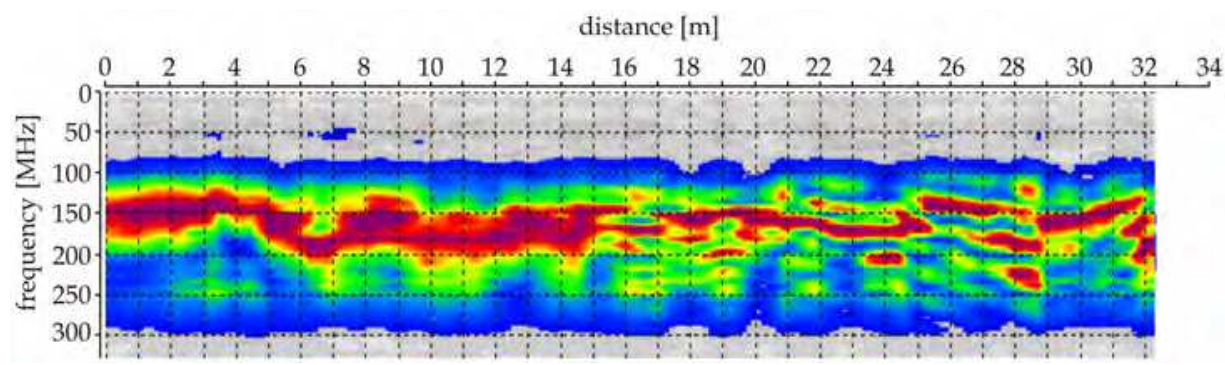

Fig. 4.2 GPR power spectra (Gołębiowski et al., 2010a)

\subsection{High-conductivity chemical contamination}

GPR can be used to detect subsurface chemical contamination through analysis of electrical conductivity profiles. Conductivity strongly affects attenuation of EM waves such that 
contaminated versus uncontaminated areas can be differentiated according to signal amplitudes in echograms (Marcak \& Tomecka-Suchon, 2010). The higher conductivity of some pollutants leads to greater attenuation and in echograms the absence of reflexes may be expected. Real time monitoring at the B-S military site revealed immediate changes in the GPR signals following injection of a high-conductivity $\mathrm{NaCl}$ solution into a zone of concentrated hydrocarbon contamination. The salt solution $(5 \mathrm{~kg}$ of $\mathrm{NaCl}$ in 30 liters of water) was injected into a well located at point $\mathrm{C}$ along the profile (Fig. 4.3). Twenty liters of gasoline were simultaneously poured into the ground surface at point $\mathrm{B}$. The injection well passes through sands of mixed grain size, overlying a clay layer. The clay layer is impermeable, separating the contamination experiment from the top of the water table at $\sim 9 \mathrm{~m}$ depth.

GPR recordings were performed within the aeration zone of a lossless geological medium using high resolution antennas $(500$ and $800 \mathrm{MHz})$ at low depth, and operating in timemonitoring mode in order to track migration of contaminants (Fig. 4.3). A mean velocity of $\mathrm{V}_{\text {mean }}=10 \mathrm{~cm} / \mathrm{ns}$, estimated from well core materials (i.e. dry sands) was used for timedepth conversions. GPR results show that attenuation increases dramatically around the borehole such that the lateral boundary of the contaminant plume was easily identified. The depth of contamination however was more difficult to locate due to the high conductivity and high attenuation of the $\mathrm{NaCl}$ solution. GPR time-monitoring of the gasoline spill showed that the horizontal length of the salt-contaminated area ( $30-32.5$ m; Fig. 4.3a-d) exceeded the original area of the spill, and did not change significantly. Twenty four hours later the contaminant plume had moved down on the profile and a hyperbola located at 30.5 $\mathrm{m}$ which probably originated from root reappeared on GPR echograms (Fig. 4.3d).

Different areas of the same water table can be contaminated from different local point sources, leading to varying levels of contamination along a given horizontal transect. In these situations, a single attenuation coefficient cannot be used to map the contamination. Changes detected in the coefficients themselves however may be used to locate boundaries of various contaminated areas. For porous media, reflection coefficients for EM waves depend not only on pore fluid type, but also on its degree of saturation (Schön, 1996). The effects of conductivity variation (ionic content of pore fluids) are evident in the GPR profile of an area of D waste dump contaminated by a high-conductivity solution, shown in Fig. 4.4. GPR data was winnowed according to an echogram time window of 20 and 35 ns to optimize recognition of the near surface aquifer and the horizon of salt contamination.

The energy component of the GPR signal reflected from the salt-contaminated horizon was subjected to a Hilbert transform, and then normalized along both horizontal and vertical axes to determine the dominant trend of energy changes (Fig. 4.4a, blue dots). Energy changes were then projected, using a cubic polynomial function, along the entire profile (Fig. 4.4a, red line). GPR results were merged with hydrological data on the basis of pore fluid conductivity (green line). Near the piezometer Pz-2, concentrated pore fluids corresponded to high energy GPR signals. To the right of Pz-2, GPR signal energy decreases rapidly until well site S-640A. The trend in energy change (Fig. 4.4a, red line) corresponds to trends in water conductivity change (Fig. 4.4a, green line). 


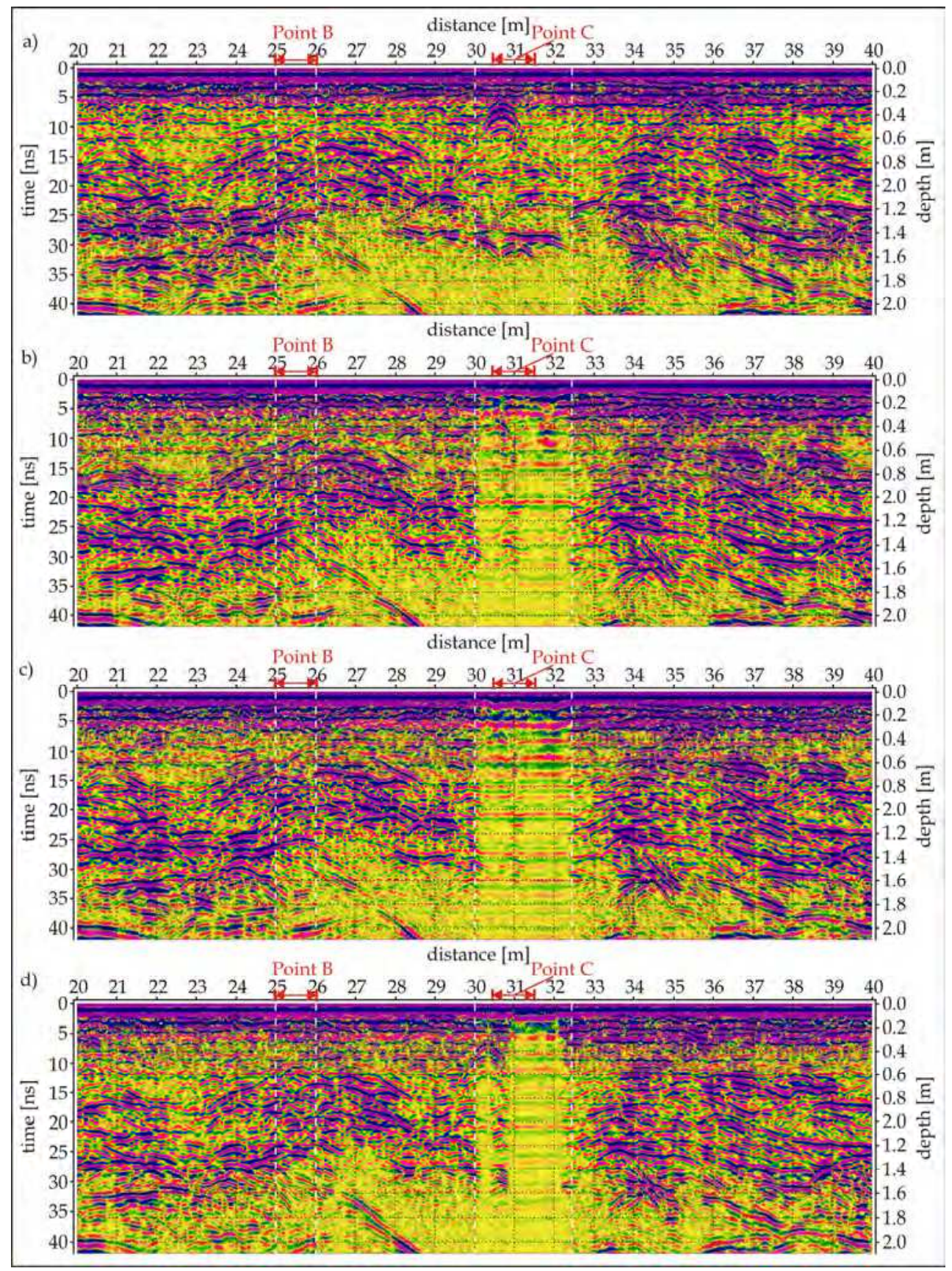

Fig. 4.3 Echograms (800 MHz antennas) from the B-S site a) before simulated gasoline spill, b) immediately after the spill, c) 3 hours after d), 24 hours after (Gołębiowski et al., 2010a) 


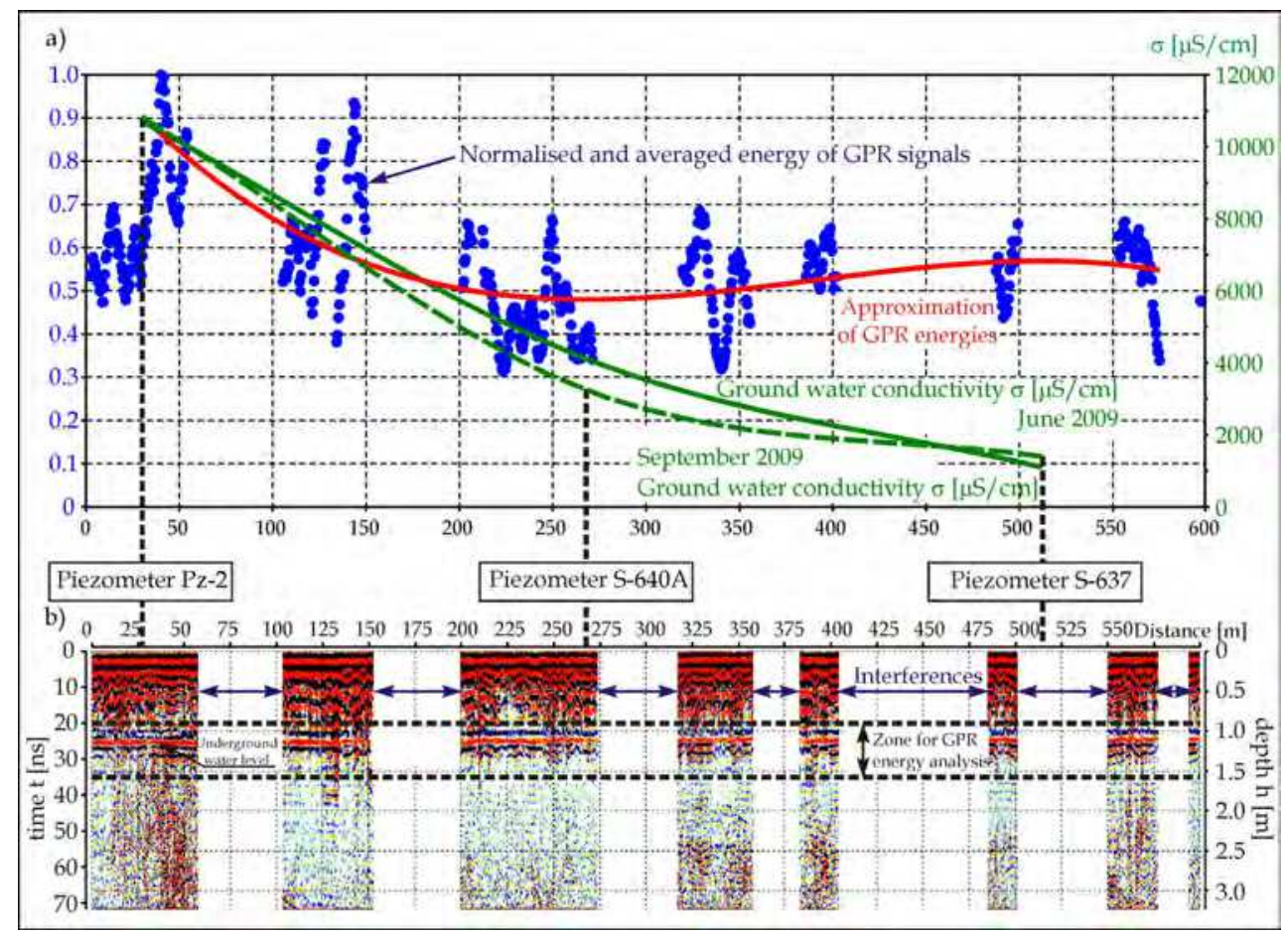

Fig. 4.4 Results of GPR investigations of an area surrounding a mining dump; a) energy distributions of GPR signals along the measurement profile and changes of ground water conductivity according to hydrogeological results; b) modified echogram - white perpendicular stripes are zones of high interference that were removed from GPR signals (Gołębiowski et al., 2010b)

\section{Microgravity investigations (Sławomir Porzucek)}

Micro-scale gravity measurements are the newest type of the gravimetric investigations in geophysics. Anomalies measured in the microgravity range are much smaller than those measured by traditional gravimetric methods. Microgravity amplitudes are only few times higher than average measurement errors for typical gravimetric devices. The newest generation of gravity meters have measurement accuracies of $\sim 5 \times 10^{-8} \mathrm{~m} / \mathrm{s}^{2}(0.005 \mathrm{mGal})$. Gravity field values for a given object depend primarily on how its bulk density is spatially distributed. For subsurface materials, shapes, sizes and the depth of objects may effect gravity measurements, but other petrophysical properties do not. Microgravity measurements can be influenced by strong winds or ground vibrations from traffic, both of which can lead to large errors. Special methods can be used to reduce the microgravity measurement error and enhance a signal/error ratio. These include shortening the time intervals between measurements to eliminate instrument drift (i.e. measurement intervals of no more than 1-3 hrs), performing replicate measurements to reduce random measurement error, and using relatively short distances between measurement stations in order to image anomalies as precisely as possible. Gravimetric modelling of the geological or human - made 
structures under investigation can assist in selecting the optimal distance interval between measurement stations. The height of the tripod on which the instrument is mounted should be measured as precisely as possible. An error of $0.03 \mathrm{~m}$ in tripod height estimation can change gravity measurements by as much as $0.01 \mathrm{mGal}$. Station location and terrain corrections are also extremely important. Improper processing of microgravity data (e.g. poorly chosen filters and so forth) may mask subsurface anomalies or create artefacts in the data. A poorly executed microgravity survey may reveal little more than the obvious Bouguer anomalies. For a carefully executed survey, microgravity anomalies with amplitudes of as little as 1.5 times the measurement error can be identified from as few as four stations, with a 99.9\% confidence level (Liu, 2007). Microgravity methods are highly sensitive to the density of subsurface objects and thus are generally used for investigating small objects at relatively shallow depths. Microgravimetric information combined with borehole data can provide 2- and 3-D density models of the subsurface. Bulk density differences apparent in microgravity data can be to used locate and identify loosened debris, such as slag heaps, salts or other industrial waste materials. Microgravity surveys are also useful in searching for natural cavities caused by karst processes. In both active and abandoned subsurface mine sites, microgravity surveys can show underground shafts, chambers and other low density features. Microgravity surveys can thus identify risks to surface activities posed by old, closed underground workings and their potential deformation.

A microgravity survey of the Wieliczka salt mine provides an example of the application described above. A $600 \times 350 \mathrm{~m}$ area was surveyed for microgravity anomalies to indentify zones in the rock mass that posed a structural risk to surface activities (Madej et al., 2001). Residual anomalies (Fig. 5.1) reflected both the geological structure of the subsurface and structures related to former mining operations. Negative concentric anomalies revealed chambers excavated by historical mining operations. The negative, concentric anomaly denoted as ' 1 ' in Fig. 5.1, was the result of weakened materials around an abandoned 16th century structure, the Lois shaft. Negative anomalies 2, 3 and 4 (Fig. 5.1) were interpreted as the main excavation area of the 16th century operation. Collapsing mine chambers and corresponding surface subsidence were recorded as early as the 16th century, indicating an on-going risk to modern surface activities. Microgravimetric surveys and modelling based on historical information enabled location of the weakened zones between level I of the mine and the surface. The negative, concentric anomalies 5 and 6 (Fig. 5.1) corresponded to excavation chambers located on level II. The relatively low amplitudes of these anomalies indicated insignificant dewatering of the strata above the chambers, and thus a slower than expected advance of the weakened zones towards the surface. A WWN-EES trending negative anomaly 7; (Fig. 5.1) is situated near a local road. This anomaly corresponded to a system of chambers that was undergoing uplift and deformation. The collapse of roof material caused structurally weakened zones above the chambers and posed significant risk to the road.

Microgravity surveys have also been conducted near a calamine deposit that was exploited during the first half of the 19th century. These investigations sought to identify shafts that posed risk to planned construction of a nearby road. The calamine deposit occurred in a Lower Triassic dolomite unit directly overlain by relatively thin $(<1 \mathrm{~m})$ Quaternary deposits. The exploited calamine horizon was about $2 \mathrm{~m}$ thick, and located at depths of $\sim 20-$ $30 \mathrm{~m}$. The mining operation consisted of a system of narrow shafts having diameters of 1.5 
$\mathrm{m}$, and occurring at depths of several meters up to several tens of meters. Archival maps provided the approximate location of these shafts. The survey was conducted using a main grid of $50 \times 50 \mathrm{~m}$, with stations spaced every $5 \mathrm{~m}$. Additional stations were implemented within the main grid, creating a secondary $17.5 \times 17.5 \mathrm{~m}$ grid with stations every $2.5 \mathrm{~m}$.

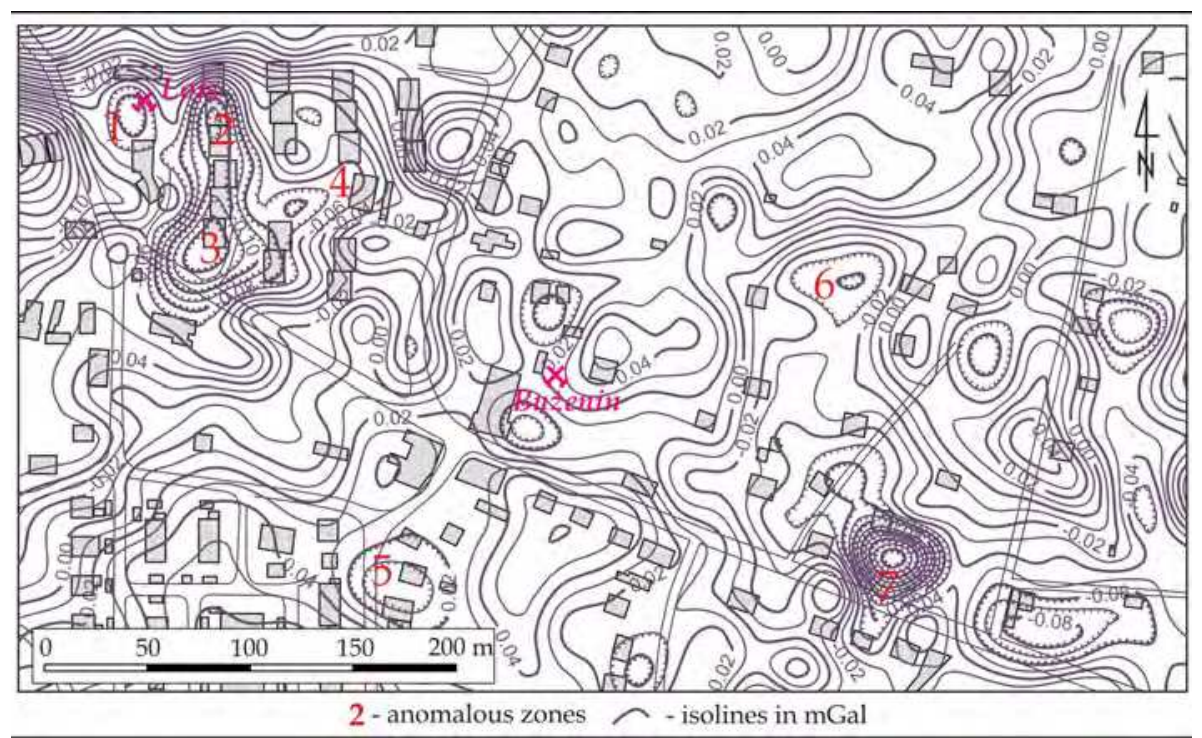

Fig. 5.1 Microgravity residual anomalies in the eastern part of the Wieliczka salt mine

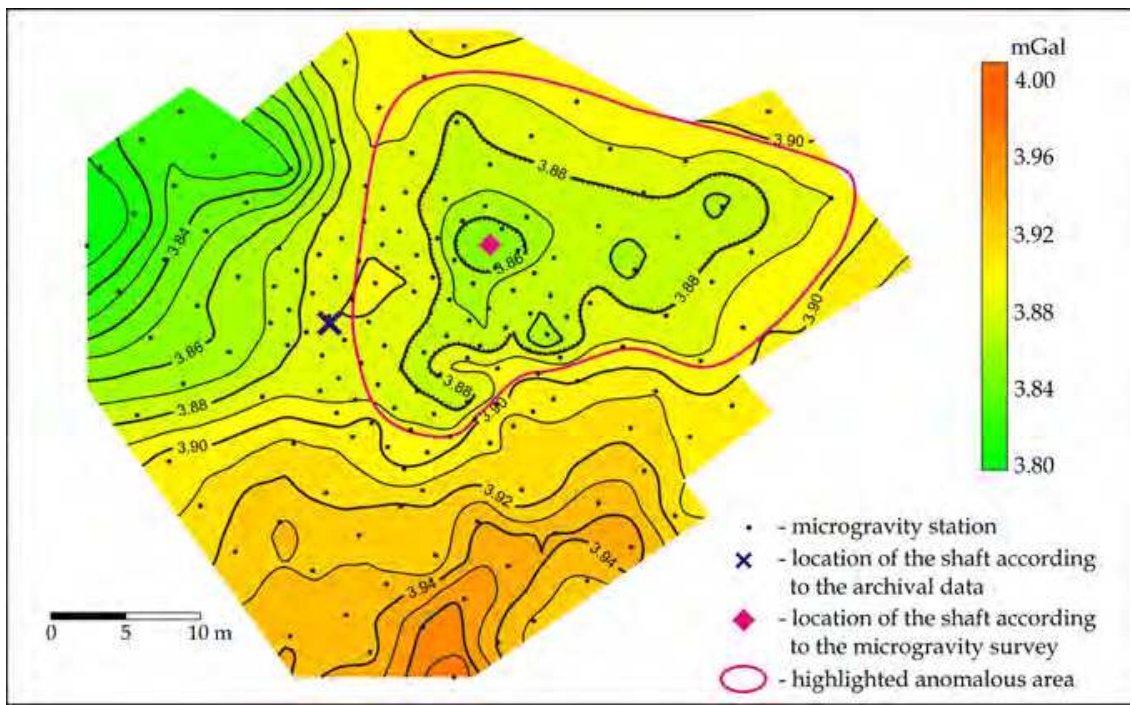

Fig. 5.2 Bouguer anomaly in the area where the shaft was suspected to be located; irregular positioning of stations is due to terrain, as well as surface and underground infrastructure 
The number of stations used in this two grid survey strategy provided the subsurface resolution necessary to locate several shafts and surrounding zones of weakness that were at risk of collapse. The highlighted area shown along with the Bouguer anomalies in Fig. 5.2, is a $40 \times 20 \mathrm{~m}$ zone that exhibited a distinct, negative gravity anomaly. This area encircled a smaller anomaly with a diameter of about $10 \mathrm{~m}$. Old mining maps indicated uncertainty concerning the location of a shaft that might have been moved from its original position in the central part of the study area. The microgravimetric anomalies clearly identified the shaft as the smaller, encircled anomaly. The larger oval-shaped anomaly surrounding the shaft was interpreted as a weakened zone, and identified as a possible risk to road construction and other surface activities.

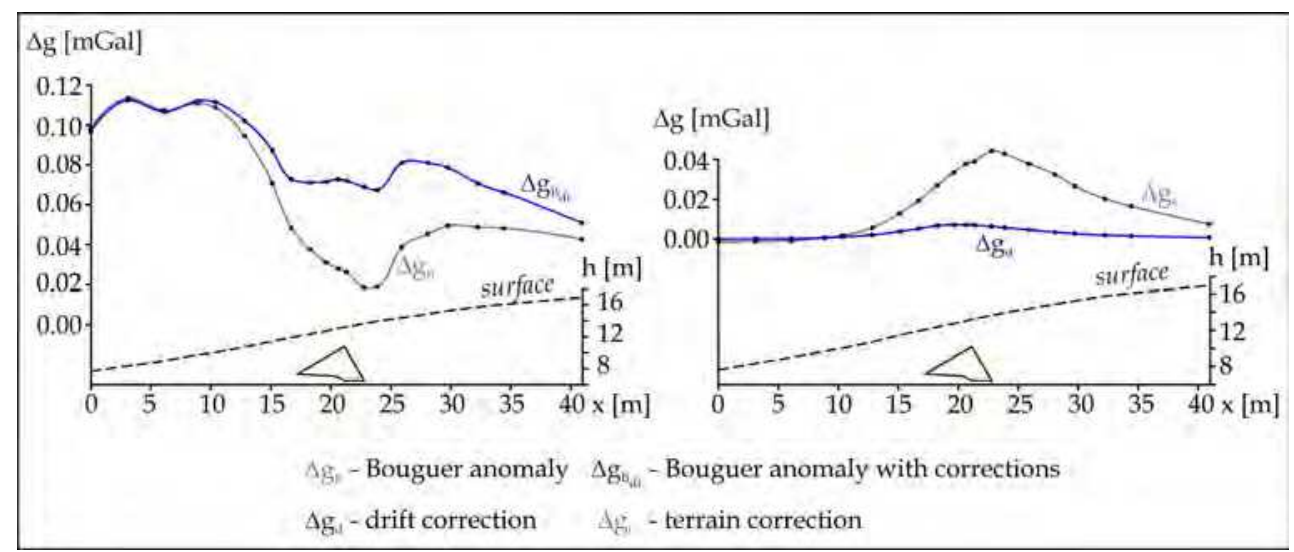

Fig. 5.3 Gravity anomalies and corrections over the subsurface drift

Microgravity surveys conducted prior to land development projects have also confirmed usefulness of the technique in risk mitigation. Results shown in figure 5.3 were collected from an area overlying a sealed mine drift, tunneled out of the local sandstone formation at the end of the 19th century. The tunnel had a total length of about $15.5 \mathrm{~m}$, a triangular crosssection with a 3-5 m base, and a height of 3-4 m. The microgravity measurement stations were positioned across the drift at intervals of $1-4 \mathrm{~m}$. The drift is visible as a relatively negative anomaly (Fig. 5.3, $\Delta \mathrm{g}_{\mathrm{B}}$ ) but the amplitude of the anomaly is difficult to determine due to the bulk density properties of the surrounding media. Excavation of the entrance to the drift increased the difficulty in detecting the structure by gravimetric methods. To minimize the impact of irregularities in the overlying terrain, the triangulation method was used to calculate a terrain correction, $\Delta \mathrm{g}_{\mathrm{t}}$ (Wójcicki, 1993). Investigators also corrected for three dimensional gravitational effects of the drift, $\Delta \mathrm{g}_{\mathrm{d}}$, using geodesy measurements to subtract the drift from the local gravity anomaly. Together, these corrections yielded a final anomaly, $\Delta \mathrm{g}_{\text {Bdt }}$ (Fig. 5.3). The final anomaly was based on points $8-9$, and bore some similarity to the initial distribution. The shape of the anomaly however did not correspond to the shape of the applied corrections. The final anomaly was thus interpreted as a fractured zone, weakened by earlier construction of the drift. These findings demonstrated that the subsurface was not entirely stable. 


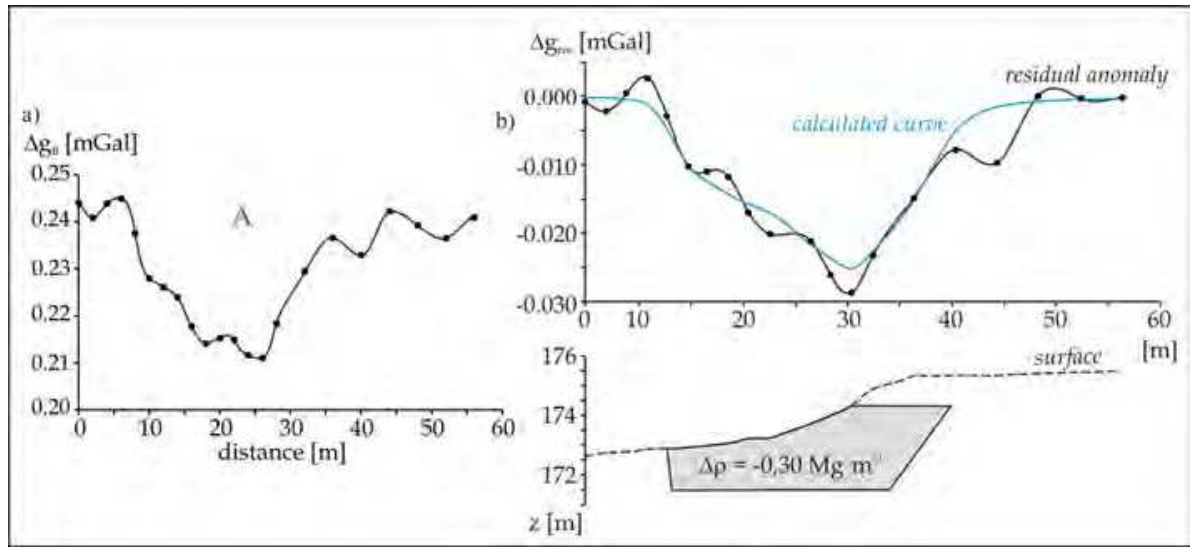

Fig. 5.4 a) Bouguer anomaly A, b) result of gravimetric modelling of the A anomaly

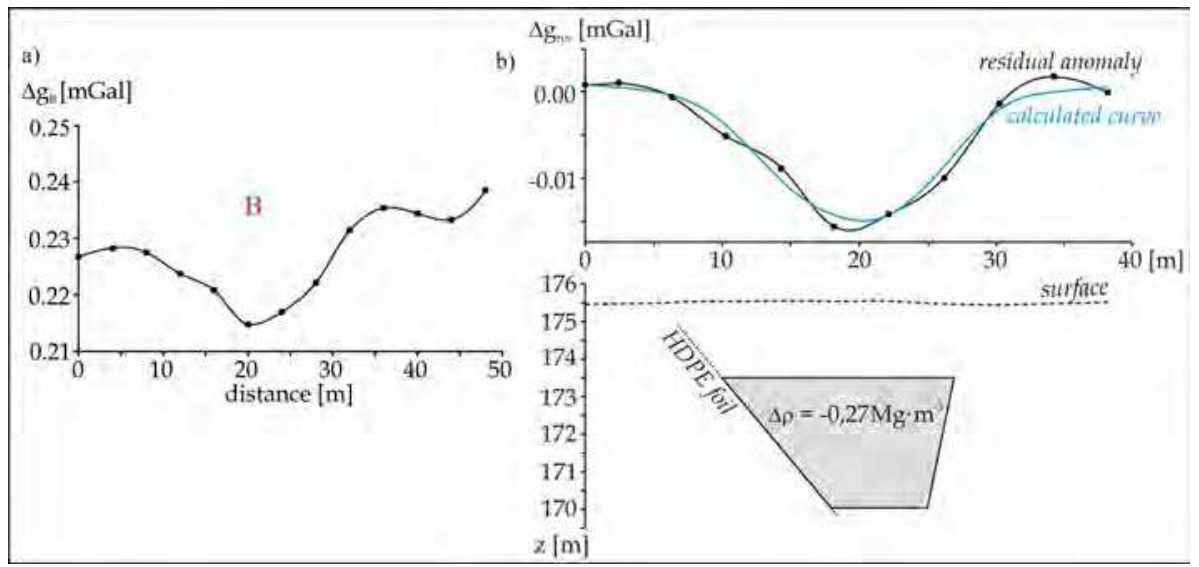

Fig. 5.5 a) Bouguer anomaly B, b) result of gravimetric modelling of the B anomaly

Microgravity can also be applied to investigate embankments and earthen dams that are at risk of water leakage and possible failure. Figures 5.4 and 5.5 show results from microgravity surveys conducted to detect zones of weakness along embankments that surround an underground water reservoir. Surveys were carried out along the embankment using a measurement interval of $2 \mathrm{~m}$. A terrain correction was applied to the data to address irregularities in the topography of the study area. The survey revealed some relatively negative anomalies, and identified several zones of weakness within the embankment. The anomaly labeled $\mathrm{A}$ is based on 14 measurement stations and had an amplitude of about 0.03 mGal (Fig. 5.4a), a factor of 3 times higher than the overall measurement error of the study. The next anomaly was a separate residual anomaly, which was then modelled (results shown in Fig. 5.4b). One zone identified in the survey was found to have a density of $0.30 \mathrm{Mg} / \mathrm{m}^{3}$ less than the average density of surrounding material in the embankment. This zone begins $2 \mathrm{~m}$ below the surface, has a thickness of about $3 \mathrm{~m}$, and contains piping that carries water from the reservoir. Poor sealing of the pipes had likely caused leakage and soil 
suffusion, resulting in this lower density zone. The second anomaly marked B had a much smaller amplitude (Fig 5.5a) and was located beneath the causeway crossing the reservoir. The anomaly is based on 6 - 7 measurement stations, and was identified with a $99.99 \%$ confidence level (Liu, 2007).

The B anomaly was modelled (Fig. 5.5b) under the assumptions that it was a zone of poorly consolidated material that extended from the bottom of the reservoir to a depth of about $2 \mathrm{~m}$ below the surface. The top of the zone of weakness was also analyzed using GPR echograms, allowing for a consistent and unambiguous model solution. The left edge of the unconsolidated zone corresponded to the location of an HDPE reservoir liner, embedded within the slope of the main embankment. In this case, microgravimetric identification of the zone of weakness demonstrated poor construction of the embankment in the study area.

\section{Magnetometry in the investigation of surface materials (Anna Wojas)}

\subsection{Origin of magnetic particles}

In near surface investigations of the Earth's crust (shallow rock formations and soils), magnetometry can be used to identify magnetic minerals, determine their origin and reveal certain physicochemical processes that may be occurring in the soil. Soil magnetometry measures a given soil's magnetic susceptibility. The technique is commonly used to assess topsoil contamination by heavy metals and to track sources of magnetic particles in urban and industrial areas. Fly ash from incinerators is among others the source of magnetic particles in urban and industrial soils. The magnetic particles derive mostly from combustion of coals containing iron sulfides. High temperature oxidation transforms iron sulfides into magnetite, maghemite, and other less common types of ferrites. Both human activities and natural processes can influence the magnetic susceptibility of soils. Magnetic anomalies can thus be caused by industrial operations, weathering of ferrimagnetic and antiferromagnetic minerals, or other pedogenic processes.

\subsection{The role of magnetic susceptibility in assessing topsoil contamination}

Surface surveys of the magnetic susceptibility of topsoil were carried out in the vicinity of a major steel operation in Krakow. The soil surrounding the steel plant is contaminated by high levels of $\mathrm{Zn}, \mathrm{Pb}, \mathrm{Cu}, \mathrm{Cd}$ and $\mathrm{Hg}$.

Magnetic susceptibility surveys were performed only in the northeastern corner of the steel plant due to limitations in site accessibility. Prevailing winds blow emissions from the plant in a southeasterly direction. A nearby railroad track was also considered as a possible source of magnetic particles in study area soils. In situ measurements of magnetic susceptibility were performed using a MS2 meter and a MS2D sensor (Bartington Co.), working from principles of magnetic induction. Measured magnetic susceptibilities of soil were in the range of 20 to $435 \times 10^{-5}$ SI units. The highest values were found closest to the steel plant (average values of $215 \times 10^{-5}$ SI units). These results confirmed fall and nearby deposition of the heavy fraction of emission particles in the soil. The outlying regions of the study area had soil magnetic susceptibility ranging from 20 to $122 \times 10^{-5}$ SI units, with an average value of $64 \times 10^{-5}$ SI units (Fig. 6.1). An oval shaped magnetic susceptibility anomaly (isoline $150 \times$ $10^{-5}$ SI units) having an easterly directed axis, highlights the direction of prevailing winds and magnetic particle transport. Magnetic and mineralogical analyses of the magnetic 
concentrate from soil samples revealed high concentrations of magnetite. Maghemite and iron sulfides were also identified. Subsequent studies have revealed a significant increase in the magnetic susceptibility of soil closest to the steel plant in the last four years (Rosowiecka \& Nawrocki, 2010). Land near the steel plant is composed of fertile soil (chernozem, brown soils, loess) and is under cultivation. Magnetometry is especially suitable for further effective monitoring of the surrounding area.

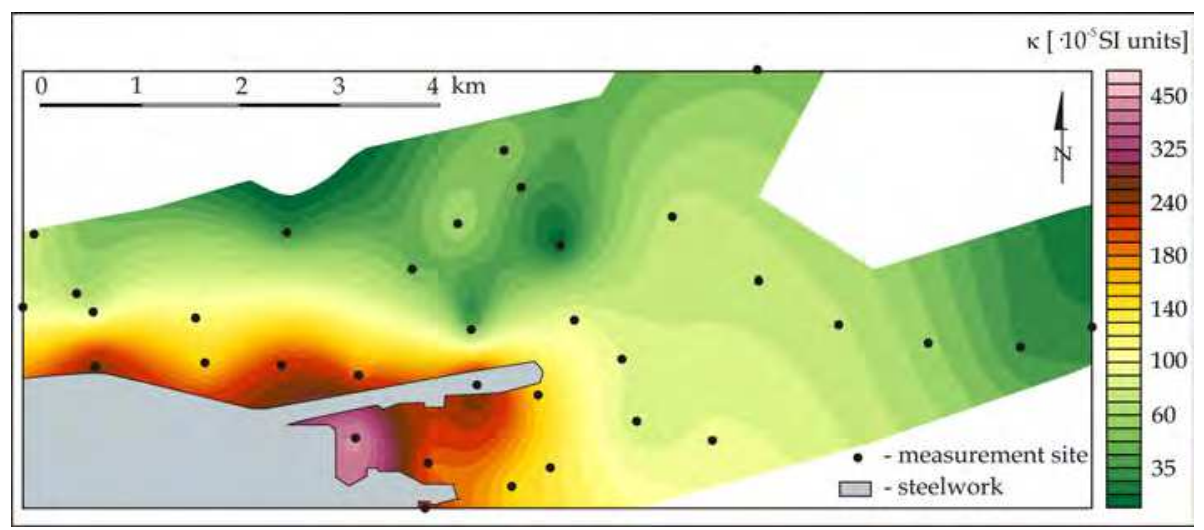

Fig. 6.1 Map of the magnetic susceptibility of topsoil in the vicinity of a Krakow steel plant

\subsection{Magnetic susceptibility of historical sequence layers}

A magnetic susceptibility study of historical sequence layers underlying the Main Market Square in Krakow revealed information about past human activity in the area. Subsurface samples collected during an archaeological excavation were analyzed in the laboratory using a MS2 meter and MS2B sensor. Analysis revealed contrasts in the magnetic susceptibility of underlying sands and overlying layers affected by anthropogenic activities (Fig. 6.2). Anthropogenic layers, which contained dark particles, fragments of bricks and sediment filled void space, often showed greater magnetic susceptibility. Overall, the historical layers had relatively weak magnetic properties.

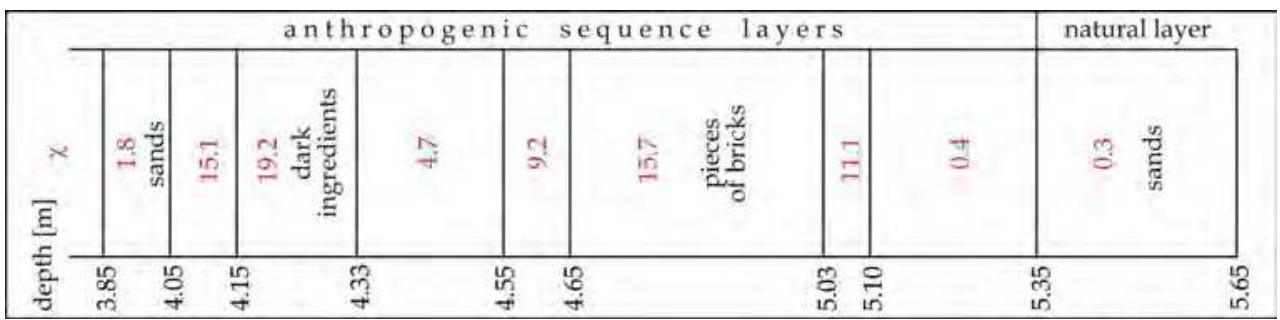

Fig. 6.2 Magnetic susceptibility of samples $\left(\chi \cdot 10^{-8} \mathrm{~m}^{3} \mathrm{~kg}^{-1}\right)$ of historical sequence layers from the Main Market Square in Krakow. 


\subsection{Magnetic susceptibility studies of ochra deposit}

Magnetometry studies of an ochre deposit in the Carpathians demonstrate the use of magnetometry in reconnaissance of potential economic deposits (Wojas, 2009). Certain iron oxy- hydroxide minerals weather to an ochre colour, which lends its name to ochre type deposits. These deposits are generally composed of goethite (yellow), hematite (red), and manganese oxides (dark hues). The magnetic susceptibility of the ochre deposit under investigation was attributable to the accumulation of secondary iron sulfides weathered from nearby rocks, and was also influenced by underlying bedrock. Magnetic susceptibility of the area was measured in situ using a MS2 meter and MS2F sensor. Low values of magnetic susceptibility (40 to $60 \times 10^{-5}$ SI units) indicated soil devoid of ochre. The ochre deposit itself was recognizable by its stronger magnetic properties, and wide ranging magnetic susceptibility values. Magnetic susceptibility of yellow and rubiginous ochre ranged from 60 to $200 \times 10^{-5}$ SI units. Crystalline rocks containing high concentrations of $\mathrm{Fe}_{2} \mathrm{O}_{3}$, and appearing as brown ochre had the highest magnetic susceptibility, from 200 to $900 \times 10^{-5}$ SI units (Kotlarczyk \& Ratajczak, 2002) (Fig. 6.3).

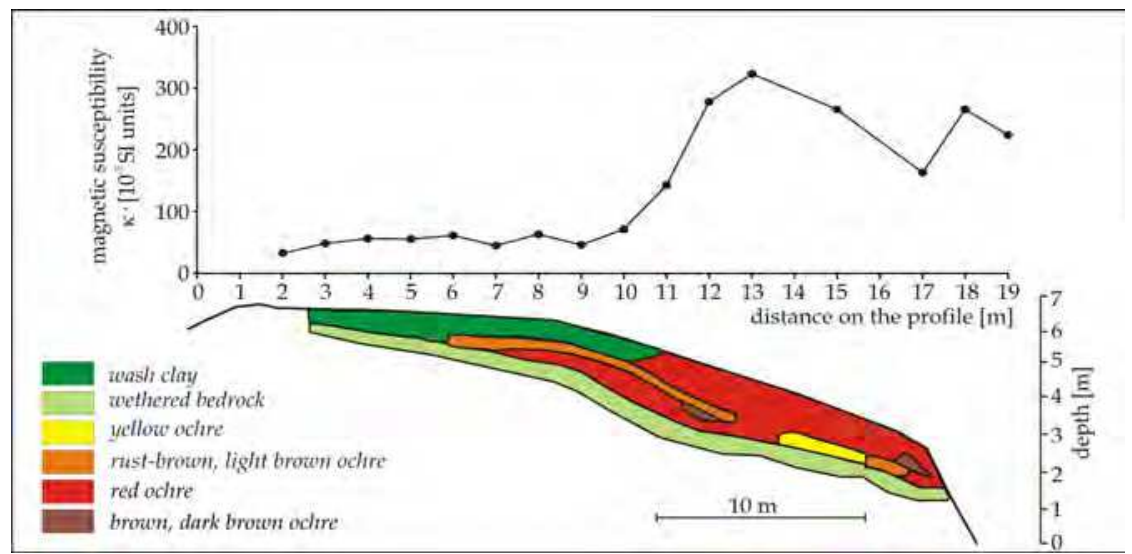

Fig. 6.3 Magnetic susceptibility values for an ochre deposit shown with a geological cross section of the deposit (Kotlarczyk \& Ratajczak, 2002).

\section{Environmental seismic investigations (Jerzy Dec)}

\subsection{Seismic evaluation of surface risks in developed areas overlying former mine sites}

Closed or abandoned coal mines are often monitored using seismic surveys, which can locate and characterize workings a few meters below the surface, to depths of up to $60 \mathrm{~m}$. Such workings may collapse or destabilize their surroundings, and thus pose a significant risk to surface activities. The stress field surrounding an abandoned working depends on the initial stress affecting the subsurface structure, which is in turn related to the depth and geometry of the working. The stress field can be evident as both continuous and discontinuous deformation (Mange \& Kochonov, 1994). Continuous deformation occurs as elastic and plastic strain in layers, which deform but maintain their continuity. Discontinuous deformation manifests as fractures and displacement of bedrock, evident in 
small scale faulting and other discontinuities (Goodman \& Shi, 1985). Discontinuous deformational features pose the greatest risk to the overlying surface. In solid rocks, seismic surveys can identify fractured zones and potential fault planes as velocity changes in seismic data. A seismic refraction survey of shallow workings at a former mine site within Carboniferous rocks, revealed differing behaviour and degrees of deformation (Table 7.1).

\begin{tabular}{|l|l|l|l|l|}
\hline $\begin{array}{l}\text { Terrain } \\
\text { Category }\end{array}$ & $\begin{array}{l}\text { Velocity, } \\
\mathrm{V}_{\mathrm{P}},[\mathrm{m} / \mathrm{s}]\end{array}$ & $\begin{array}{l}\text { Structure of } \\
\text { Carboniferous rocks }\end{array}$ & Fractures & Hazards to surface \\
\hline A & $>1900$ & contiguous rock & None & none \\
\hline B & $>1900$ & $\begin{array}{l}\text { separate blocks of rocks, } \\
\text { contiguous rock within a } \\
\text { block }\end{array}$ & None & $\begin{array}{l}\text { infiltration hazard at } \\
\text { block contacts }\end{array}$ \\
\hline C & $1500-1900$ & $\begin{array}{l}\text { continuous surface of } \\
\text { uppermost Carboniferous }\end{array}$ & fractured rocks & infiltration hazard \\
\hline C1 & $1500-1900$ & $\begin{array}{l}\text { separate blocks of rocks, } \\
\text { displaced }\end{array}$ & $\begin{array}{l}\text { fractured blocks } \\
\text { of rocks }\end{array}$ & $\begin{array}{l}\text { discontinuous } \\
\text { deformation hazard }\end{array}$ \\
\hline D & $1100-1500$ & $\begin{array}{l}\text { fractured rock, possible } \\
\text { blocks of rocks }\end{array}$ & $\begin{array}{l}\text { highly fractured } \\
\text { rocks }\end{array}$ & $\begin{array}{l}\text { infiltration and } \\
\text { discontinuous } \\
\text { deformation hazards }\end{array}$ \\
\hline$<1100$ & destruction of rock mass & $\begin{array}{l}\text { highly fractured } \\
\text { rocks, fissures }\end{array}$ & $\begin{array}{l}\text { high risk of } \\
\text { discontinuous } \\
\text { deformation }\end{array}$ \\
\hline
\end{tabular}

Table 7.1 Seismic categories of Carboniferous rocks

\subsubsection{Seismic surveys in developed areas}

Standard seismic surveys often cannot be conducted at construction sites in developed areas due to their disruptiveness, risks to nearby inhabitants, and accessibility of the area surrounding the site.

In these cases, the uppermost body of bedrock beneath the surface can be imaged by seismic refraction tomography (Fig. 7.1). This technique interprets changes in wave velocity during $\mathrm{P}$-wave propagation, in this example, through a near-surface Quaternary deposit (AB and $C D$ in Fig. 7.1; velocity $=V_{0}$ ) and underlying bedrock (BC in Fig. 7.1; velocity $=V_{1}$ ). P-wave velocity for the Quaternary deposit was much smaller than that of the Carboniferous rocks $\left(\mathrm{V}_{0}<\mathrm{V}_{1}\right)$, which resulted in a relatively small critical angle of refraction $(\mathrm{i}<10 \mathrm{o})$. The near surface Quaternary deposit was only a few meters thick. AB was thus insignificant, and the distance $\mathrm{BC}$ was assumed to equal that of $\mathrm{AD}$. The errors for estimating unit thickness and their associated velocity changes were based on critical angle, $i$, and refractor depth, $h$.

Given an AD thickness of $100 \mathrm{~m}$, refractor depth $\mathrm{h}$ of $2-8 \mathrm{~m}$, and i equal to $5-15^{\circ}$, errors were relatively small, ranging from $0.3-4.3 \%$. In the model described above, the initial arrival time for the refracted signal $T_{A B C D}$ (traversing $A B C D$ ), could be approximated as the time necessary to traverse BC (Dec, 2004). The study used a seismic source located at point $B$, and receiver at point $C$, which reduced the initial arrival time to $T_{A B}$, or time necessary to traverse distance $\mathrm{AB}$. Arrival times were used to construct a tomographic image of the Pwave velocity distribution for rocks beneath the Carboniferous surface. Velocity values were 
directly correlated to the composition and physical state of the subsurface material. Fractures and void space for example were evident as areas of reduced velocity.

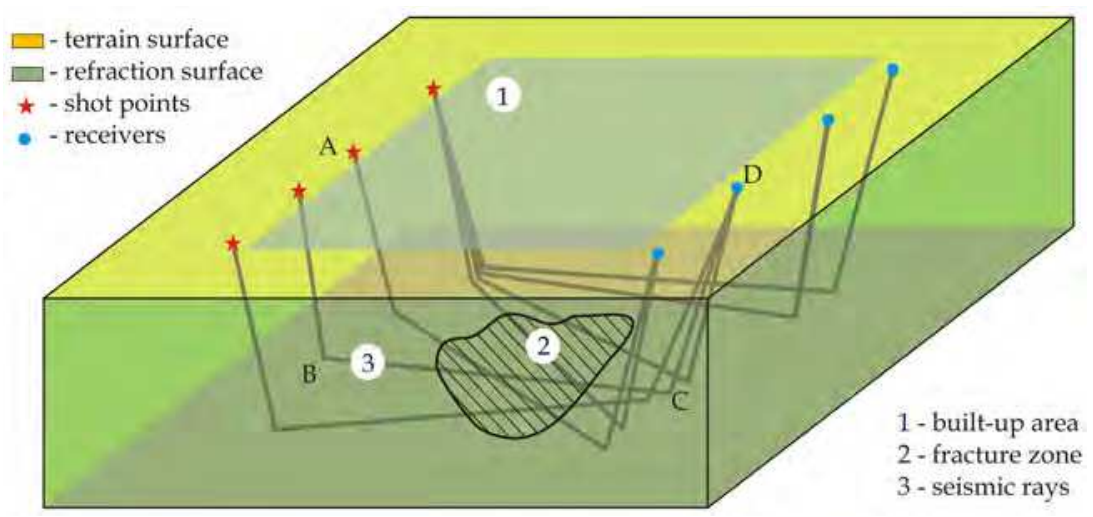

Fig. 7.1 Seismic refraction tomography: the study model

\subsubsection{Evaluating ground surface stability risks}

A survey carried out at the K-K coal mine in Katowice, Poland was used to image the continuity and stability of a subsurface Carboniferous unit, and the risk it posed to surface activities. The survey imaged old shallow $(20-50 \mathrm{~m})$ workings dating from the late $19^{\text {th }}$ to the $20^{\text {th }}$ century, which were located in upper parts of the Carboniferous unit. The workings have caused extensive fracturing of the unit $\left(\mathrm{V}_{\mathrm{P}}<1200 \mathrm{~m} / \mathrm{s}\right)$ and cavity migration towards the surface. Fractures from the working significantly increase the risk of ground surface deformation and failure. Due to urban development in the area, a standard seismic profile was not possible; refraction seismic tomography was used instead.

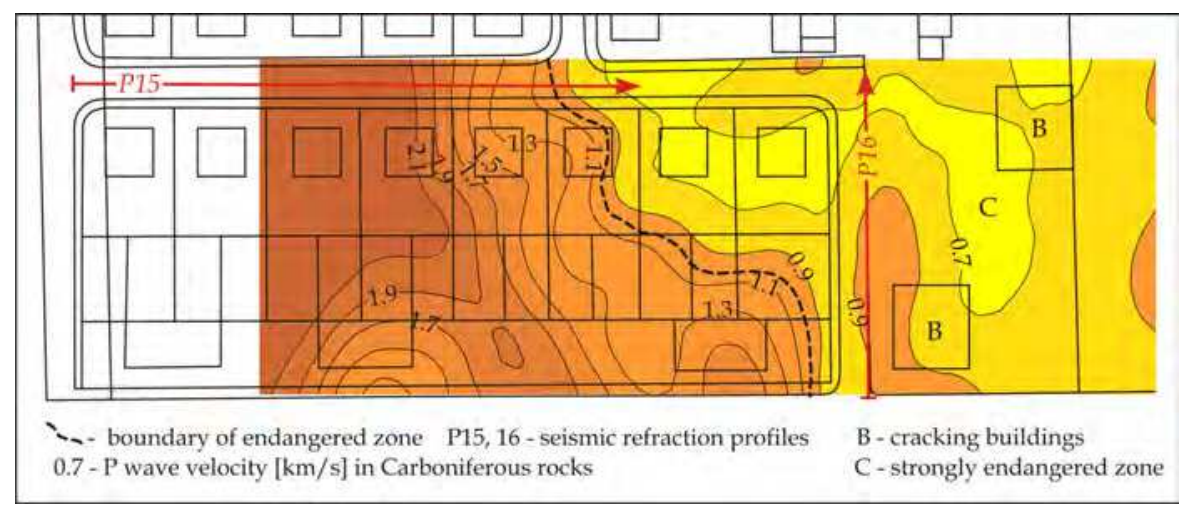

Fig. 7.2 Location and results (velocity distribution) of a tomographic study conducted in a developed area, Katowice-D, Poland; colours indicate velocity values [km/s] from the Carboniferous surface 
Quaternary deposits that overly the Carboniferous unit include several meters of loamy sands and clays. The Carboniferous unit is comprised of sandstone, mudstone, shale and coal seams. The contact between the two units is an angular unconformity (lower units dip $\sim 6-8^{\circ}$ ) with a pronounced erosional surface. The survey showed numerous locations where the rock mass was continuous and not fractured, as indicated by velocities of $V_{P}>1900 \mathrm{~m} / \mathrm{s}$ (Table 7.1). Most of the subsurface in the study area however was strongly fractured and appeared as a discontinuous refraction boundary $\left(700>\mathrm{V}_{\mathrm{P}}>1800 \mathrm{~m} / \mathrm{s}\right)$. A representative location of the study area was the Katowice-D district (Fig. 7.2), where the Carboniferous unit exists in each of the different physical states or categories as described in Table 7.1.

Velocity, $V_{\mathrm{P}}$, from profile 15 was equal to around $\sim 2200$ to $1100 \mathrm{~m} / \mathrm{s}$ (Fig. 7.3), and the state of the Carboniferous surface (B-C2) was categorized as significantly fractured near the edges of the profile. The adjacent profile 16 had $V_{P}=900 \mathrm{~m} / \mathrm{s}$, and rock structure category $\mathrm{D}$, having no contiguous structure. Data from boreholes drilled in the survey area verified results of the seismic survey. Concrete was then injected into the top parts of the Carboniferous unit through the boreholes. The concrete was readily absorbed by the fractures and cavities.

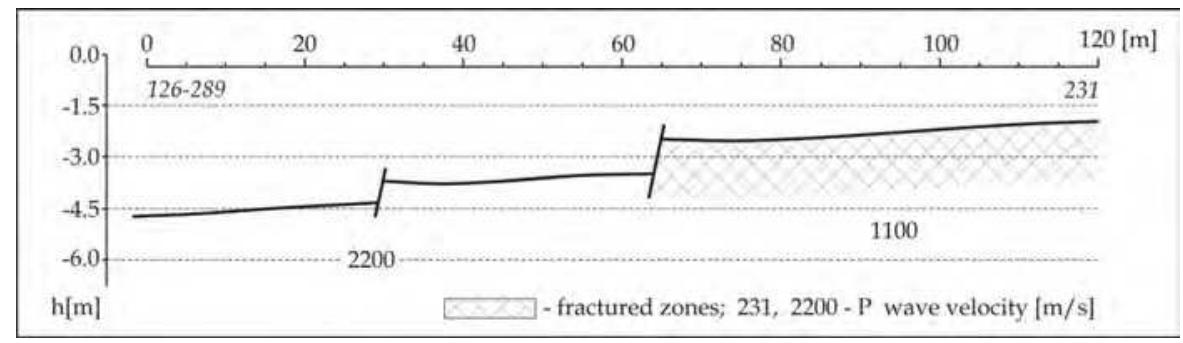

Fig. 7.3 Cross-sections along refraction profile 15, Katowice-D, Poland

The $160 \times 70 \mathrm{~m}$ investigation area was located between two streets, and was thus divided into two sections (Fig. 7.2). Measurements were performed using a TERRALOC MK6 seismic system. Accelerated weight-drop source EWG-III and L-40B geophones $(100 \mathrm{~Hz})$ were used to record seismic sources. Descriptive results for the structure and physical state of the Carboniferous rocks are presented as categories in (Table 7.1). Figure 7.2 illustrates that the subsurface structure was unstable throughout most of study area (category B-D). Two different zones of the study area were distinguished based on the physical state of the subsurface (Fig. 7.2). The left-hand zone was characterized by fractured rock (category B-C2) and the right-hand zone was characterized by rocks that had been pulverized (category D). A contour outlining material with velocity $V_{P}=900 \mathrm{~m} / \mathrm{s}$, separates the zone with a fractured foundation. A low velocity anomaly $\left(\mathrm{V}_{\mathrm{P}}<700 \mathrm{~m} / \mathrm{s}\right)$ is probably related to old workings (cavities) which connect to the ground surface through a system of fractures. Such zones are at risk of infiltration, suffusion and ground collapse. In conclusion, refraction tomography was effective in determining rock properties beneath a developed area, where traditional seismic methods could not be used. Fracture zones overlying old mine workings were evident as strong velocity anomalies, whose magnitude could be correlated to the degree of rock fracturing. Seismic refraction methods are thus suitable for evaluating surface risks of abandoned mines in developed areas. 


\subsection{High resolution seismic techniques for investigating the economic sulphur deposits}

Exploitation of sulphur deposits using the underground 'melting' method (also referred to as well mining, or hydrodynamic process mining, or Frash method) poses significant environmental risks. A seismic investigation of the Osiek sulphur mine (Staszow district, Poland) illustrates the usefulness of seismic surveys in managing these risks. Sulphur is extracted at Osiek by pumping hot extraction fluids into the subsurface sulphur deposit. Melted, liquid sulphur is then brought to the surface through a series of production wells. Although the Osiek mine is the only operation in the world to use this technique, extraction at Osiek as well as similar oil and gas operations, put soils, ground water, and air quality at risk. Mine operators can manage risks by closely monitoring the melting process, and incorporating real time geophysical data into risk management decisions. Seismic surveys can specifically be used to monitor the spatial range of the melting zone (Dec, 2010) (i.e. its rate of expansion), and potential subsidence of the overburden (materials overlying the deposit). A seismic investigation of the Osiek mine site illustrates the application described above. Fluid removal of sulphur at the Osiek mine decreases the mechanical strength of porous limestone host rock, which can fail under the pressure of the overburden. Melting zones are not only at risk of failure, but melting may also cause changes in elastic properties of the areas surrounding the extraction zone. Such changes can induce subsidence and other disruptions to the subsurface stress field. High-resolution reflected seismic profiles provide accurate images of the structure of the deposit, its overburden, and signs of deformation in the surroundings. Seismic methods were also used to monitor the melting front and to watch for potential initiation of subsidence troughs, whose risks can be better managed by early detection (Al-Rawahy \& Goulty, 1995). Changes in subsurface structure imparted by the Osiek melting method were detected by seismic surveys as early as a month after melting operations began at a particular well site. The extraction fluids used to control the size and expansion rate of the melt zone can also be used to manage subsidence troughs. Under these circumstances, pressure and flow direction of the extraction fluids were used to shape the subsidence trough in a way that prevented the destruction of adjacent wells located along the trough margins.

\subsubsection{Field methods for the Osiek mine seismic survey}

Seismic measurements imaged the Miocene unit being exploited by the mining operation and underlying sub-Tertiary strata, at depths of $20-200 \mathrm{~m}$. The survey was conducted along lines defined by the positions of overlying production wells (Fig. 7.5). A short spread, high frequency seismic source (Elastic Wave Generator EWG-III, $250 \mathrm{~kg}$ accelerated weightdrop), and high frequency geophones $(100 \mathrm{~Hz})$ were used to obtain high vertical and horizontal resolution (Brouwer \& Helbig, 1998). In order to avoid errors caused by heterogeneities in the subsurface, a split spread with a $100 \mathrm{~m}$ interval was applied. Geophones were positioned at $5 \mathrm{~m}$ intervals (trace spacing). Near offset was equal to $50 \mathrm{~m}$ and far offset was equal to $165 \mathrm{~m}$. The $5 \mathrm{~m}$ trace spacing and $1 \mathrm{~m}$ shot interval gave CMP resolution equal to $2.5 \mathrm{~m}$ and a 24 fold CMP gather.

The majority of the profile was collected using the full 24 fold CMP gather. For parts of the study area that were difficult to access, a 24 channel end-off spread with a 12 fold CMP gather was used. Vertical stacking of signals helped reduce ambient noise caused by mine 
equipment. This procedure combines signals recorded from the same seismic source and at the same geophone location (Upadhyay, 2004). As many as 20 stacked signals were required to generate high resolution records for some areas. A model of the deposit and the seismic profile obtained from the 24 channel end-off spread are shown in figure 7.4. The following data processing procedures were applied to enhance profile resolution: field static correction, spherical divergence (spreading) correction, refraction static based on the first break picking, surface consistent scaling, surface consistent deconvolution, shaping filter based on the refraction wavelet, Ormsby filter 40/60-150/200 Hz, iterative velocity analysis, $\mathrm{NMO}$, residual static correction, and CMP stacking. Several profiles, referred to as time sections, were recorded throughout the extraction process to monitor temporal changes associated with various phases of extraction.

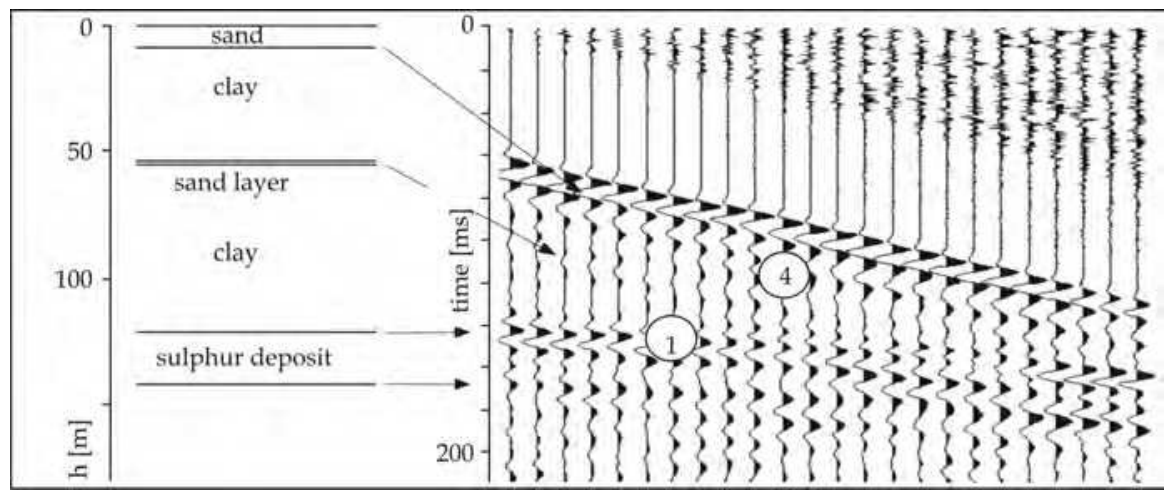

Fig. 7.4 Deposit model and seismic raw record; 1-top of the deposit, 4 sand horizon in the overburden

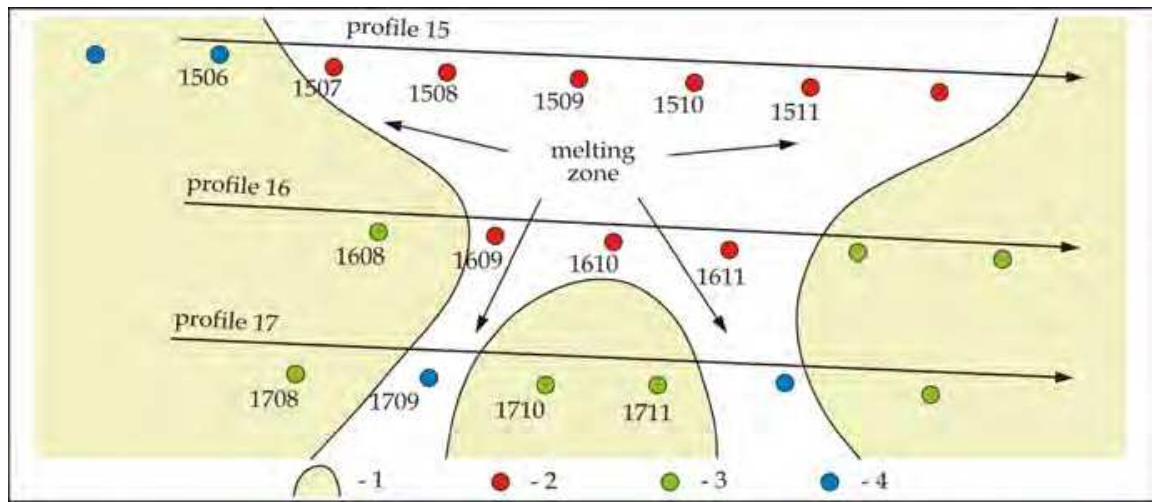

Fig. 7.5 Osiek mine, location of seismic profiles; 1-unexploited zone, 2-producing wells, 3-wells prepared for exploitation, 4-wells with increasing temperature 


\subsubsection{Influence of melting on the overburden}

Time sections obtained prior to the initiation of melting revealed a number of continuous reflectors in the overburden. Profiles collected during extraction show distinct changes in the top surface of the deposit (above the producing formation), which usually appeared as discontinuities in previously continuous reflectors. These changes were also evident as changes in amplitudes and even disappearance of certain reflectors.

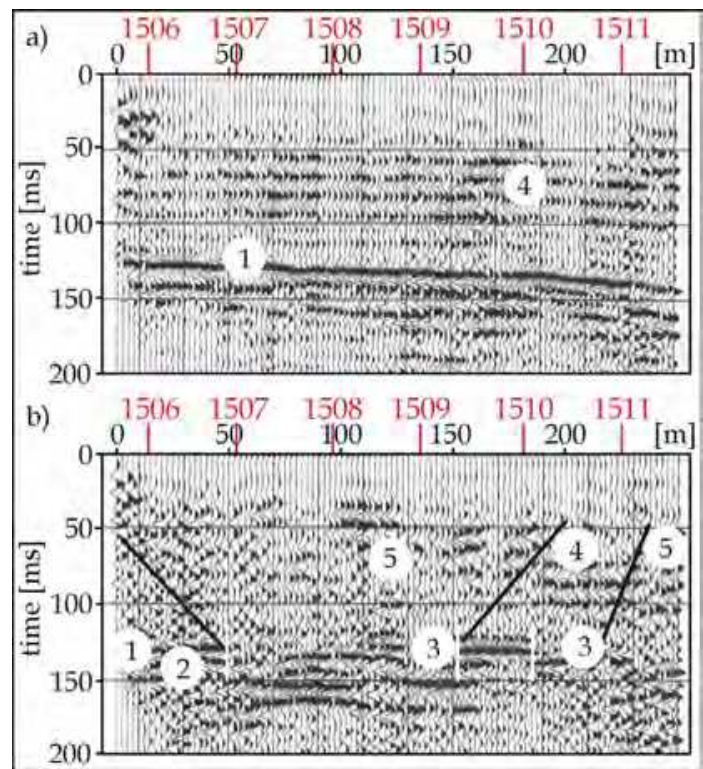

Fig. 7.6 Seismic sections of the sulphur -bearing horizon obtained before (a) and during exploitation (b); 1-top of the sulphur horizon, 2-unexploited zone, 3-exploitation zone, 4horizons in overburden, 5 -deformation zone

Anomalies were also evident in seismic images of the overburden material. These anomalies (50-100 ms) appeared as discontinuities in specific reflectors, indicating subsidence of the formation. Time sections of profile 15 collected prior to initiation of melting, and 3 months after initiation of melting, showed changes in the subsurface (Fig. 7.6). Asymmetric subsidence resulted from destruction and collapse of the overburden strata, which was inturn related to the expansion rate and direction of the melting front. Intuitively, observed deformation was more severe in areas having more closely spaced production wells (Fig. .7a). Deformation of the overburden also appeared to correlate with the boundary between exploited and unexploited zones of the deposit. The most intensive deformation and overburden subsidence (broken continuity of strata; to the right of 1609 well), corresponded to the boundary of an unexploited part of the deposit. The 1609 well was destroyed under similar conditions, by stresses generated in the deformation zone. If deformation-induced stresses generated along planes within the overburden formation attain critical values, production wells within the subsidence zone can be subjected to shearing and ultimate destruction. This scenario (Fig. 7.7b) is evident in the time section profile presented in figure 7.7a. 


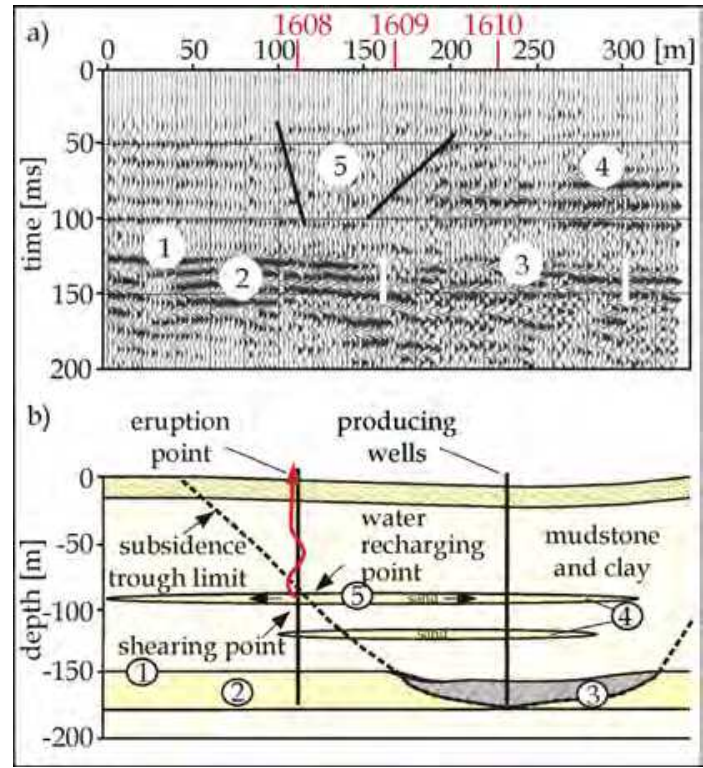

Fig. 7.7 a) Seismic image of overburden layers and associated deformation zone;

b) Subsidence effects around exploitation zone and the area of subsidence trough; numerical labels the same as those in Fig. 7.6

\subsubsection{Studies of water flow in the Osiek subsurface}

Infiltration of fluids into the overburden can change the elastic properties of the materials therein, and thus cause the disappearance of natural reflectors observed in previous surveys. For example, fluid migration into arenaceous horizons of the overburden caused the disappearance of a reflector, demonstrating the physical response of subsurface materials to infiltration. The water infiltration occurred within a zone of the overburden that allowed investigators to identify the source of the infiltration. Successful location of the leak allowed for repair of the failed component. Subsurface monitoring of infiltration is recommended if a given recharge point (e.g. the C-45 recharge well) is located a significant distance from its discharge (eruption) zone (Fig. 7.8). The unexploited part of the deposit is located to the left and the melting-induced destruction zone is located on the right side of figure 7.8. Strong subsidence above the exploited area caused failure of the C-45 well and fluid infiltration into the overburden strata.

The disappearance of seismic reflectors in profiles affected by the infiltration event demonstrates that the zone of infiltration can be precisely identified (Fig. 7.9). Near the F-71 well for example, all seismic reflectors found within the overburden strata disappeared. Fluid infiltration of the arenaceous horizon at $95 \mathrm{~m}$ depth was also visible. Post infiltration seismic profiles also indicated that subsidence associated with exploitation of this particular area may facilitate water migration not only within the arenaceous horizon, but also through horizons of the overburden. The broad infiltrated zone around the C-45 well narrowed into an elongated flow path directed to the F-71 well, a site of intensive surface discharge. The system of parallel seismic sections allowed precise imaging of the direction and width of the flow path. 


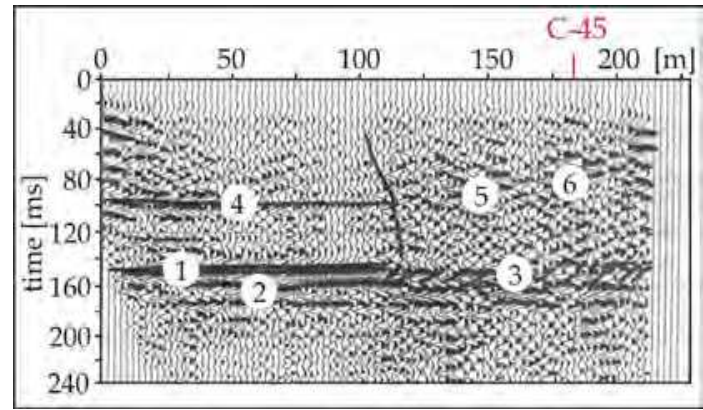

Fig. 7.8 Seismic section in the zone around the failed well; 1-top of the bed, 2-unexploited zone, 3-exploitation zone, 4-horizons in the overburden, 5-deformation zone, 6-recharge zone.

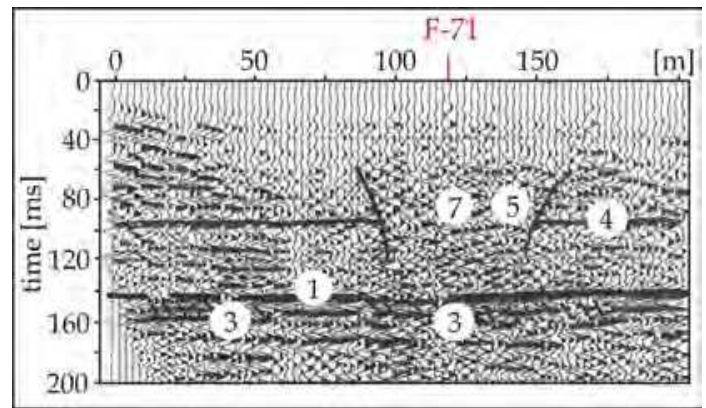

Fig. 7.9 Seismic profile of a zone affected by extraction fluid migration from the overburden to the surface; labels 1 through 6 are the same as in Fig. 7.8; 7-flow and eruption zone.

\subsection{Evaluating landslide stability from seismic surveys}

The current geophysical methods for investigating landslides assume that each landslide must be analyzed separately. Various geophysical methods, including seismic refraction, geoelectrical profiles, and GPR can be integrated in geophysical analysis of landslides. Integrated methods were used to study a landslide that occurred in the Krynica subunit of the Magura unit, Outer Carpathians. The landslide covered approximately 3 hectares, and was located on a slope that descends to a river. The slide surface was initiated in thin, weathered subsurface rocks, and in outcrops of the Eocene Piwniczna sandstones (the sandstone member of the Magura unit). The Piwniczna sandstone is a massive, thickly bedded $(1.5-6 \mathrm{~m})$ unit with conglomeratic horizons. Fractures are rare in the unit. Within the Piwniczna, packets of medium to fine grained, rhythmically bedded flysch occur. These beds are generally several meters thick. Thin-bedded sandstones and marly shales were also observed in the eastern part of landslide. Field measurements of the landslide were difficult due to the steep gradient of the slope, dense vegetation, and damage to slide surface caused by recent minor reactivation. Nevertheless, eight seismic refraction profiles, three geoelectrical profiles, and six GPR profiles were collected from accessible areas. The seismic boundary separating the overburden $\left(\mathrm{V}_{\mathrm{P}} \sim 1000-1400 \mathrm{~m} / \mathrm{s}\right)$ and basement $\left(\mathrm{V}_{\mathrm{P}} \sim 2200-2500\right.$ $\mathrm{m} / \mathrm{s}$ ) were distinctly visible on seismic records (Fig. 7.10). 


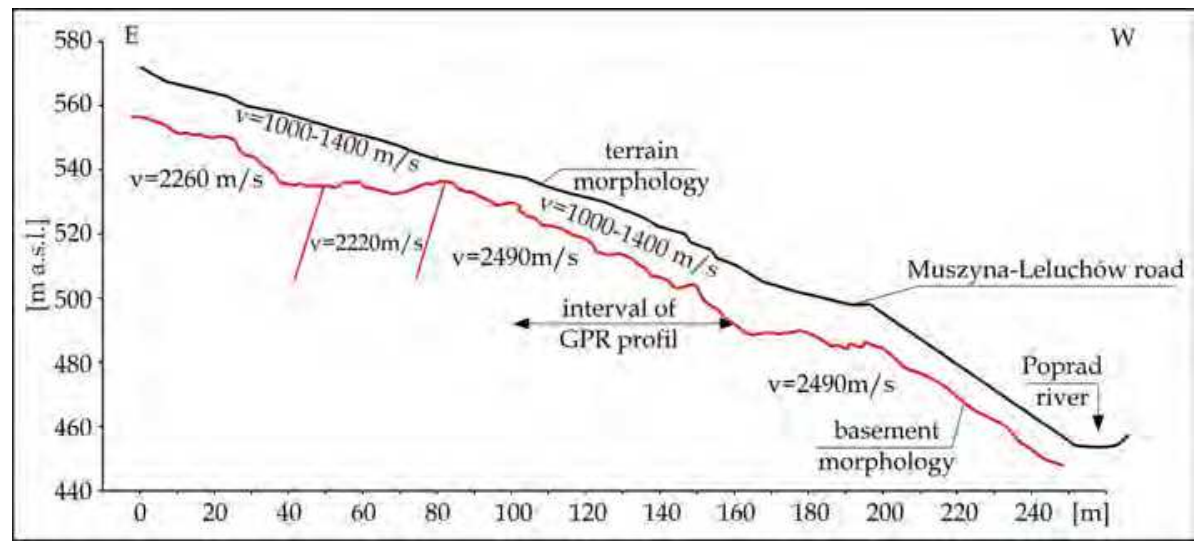

Fig. 7.10 Landslide - seismic refraction depth section.

Geoelectric profiles were strongly influenced by the water saturated overburden, and were consistent with seismic profiles. The GPR survey showed several areas of the overburden where shallow layers of differing inclination highlighted the landslide's progression. Large blocks of rocks within the slide probably caused the irregular movement observed in the overall landslide. Visible variations in bedrock morphology (Fig. 7.10) provided evidence that the landslide plane formed within flysch strata. Geophysical investigations enabled determination of the depth and horizontal range of the landslide. The integrated interpretation was used to select sites for geotechnical boreholes, and forecast the landslide's future stability. These interpretations suggested that even slight shifts in geotechnical features could reactivate the landslide and jeopardize a nearby road. The risk is a natural consequence of the geomorphology of the study area, where fine-grained units within the subsurface can easily become natural slide surfaces.

\section{Conclusions}

The examples presented above demonstrate how geophysical methods can be used in near surface applications such as resource development, engineering, archaeology, mitigation, remediation and environmental protection. In all cases, the available geophysical techniques were applied using modified methodologies, field measurements and processing strategies.

Contemporary catastrophic events and Earth processes in macro scale force application of current geophysical methods in recognition of their results influencing the environment. Heavy rains and floods in Poland in the last ten years gave rise to intensive works in identification and recognizing and mitigation of landslides. Results of geophysical surveys including GPR and shallow seismic refraction were integrated for investigation of landslides. The presented investigations enabled determination of the depth and horizontal range of the landslide. The integrated interpretation showed sites for geotechnical boreholes, and forecasted the landslide's future stability. Geophysical surveys were also useful in preparing the strategy for landslide risk mitigation and helped in the detailed understanding of the internal structure of the landslides, especially the slide surface. 
Results of GPR and microgravity surveys turned out also to be highly effective in locating zones of weakness in river embankments. The results of field measurements enabled qualitative determination of the embankment's inner structure and basal materials. It was shown that GPR and microgravity methods were useful in the investigation of embankments and earthen dams that are at risk of water leakage and possible failure.

Well known applications of GPR in archaeology were also presented together with new area oriented to identification of low conductivity and high conductivity contaminations of subsurface formations.

Seismics in tomography mode and refraction mode and microgravity surveys were shown as methods useful in identification and recognition of weak zones in the industrial areas of former and contemporary mining activity. Fracture zones overlying old mine workings were evident as strong velocity anomalies and low density anomalies, whose magnitude could be correlated to the degree of rock fracturing suitable for evaluating surface risks of abandoned mines in developed areas.

Magnetic susceptibility measurements in situ and in laboratory were presented as an useful tool in effective monitoring of anthropogenic influences on the environment in the past (historical layers) and in tracking the contemporary pollution by iron compounds. Magnetic anomalies are also the evidence of weathering of ferrimagnetic and antiferromagnetic minerals, or other pedogenic processes.

Universal petrophysical formulas were demonstrated to combine empirical laboratory data with geophysical and well logging measurements and theoretical expectations and parameters forming relationships useful in a consistent, quantitative geophysical interpretation. Exemplary values of parameters for the lithology types were presented in tables and figures to illustrate the level of parameters values frequently found in the near surface formations.

\section{Acknowledgments}

Authors would like to thank Ms Teresa Staszowska for preparing the figures and text edition.

\section{References}

Al-Rawahy, S., Y., S. \& Goulty, N., R. (1995). Effect of Mining Subsidence on Seismic Velocity Monitored by a Repeated Reflection Profile, Geophysical Prospecting, Vol. 43, pp. 191-201.

Annan, A., P. (2001). Ground Penetrating Radar. Workshop Notes, Sensors \& Software, Canada.

Brouwer, J. \& Helbig, K. (1998). Shallow High-Resolution Reflection Seismics. Elsevier Science Ltd., Amsterdam.

Daniels, D., J. (2004). Ground Penetrating Radar - 2nd Ed., The Institution of Electrical Engineers, ISBN 978-0-86341-360-5, GB.

Dec, J. (2004). Seismic Survey to Evaluate the Danger of Ground Surface Damage in Built-Up Terrain in Mining Areas. Polish Journal of Environmental Studies, Vol. 13, pp. 70-73. 
Dec, J. (2010). High Resolution Seismic Investigations for the Determination of Water Flow Directions During Sulphur Deposits Exploitation. Acta Geophysica, Vol. 58, pp. 5-14.

Gołębiowski, T., Tomecka-Suchoń, S., Marcak, H. \& Żogała, B. (2010a). Aiding of the GPR Method by the Other Measurement Techniques for the Liquid Contamination Detection, XIII International Conference on Ground Penetrating Radar, Lecce/ 21-25 June 2010.

Gołębiowski, T., Marcak, H., Tomecka-Suchoń, S., Zdechlik, R., Zuberek, W. (2010b). Use of Geophysical Methods for the Assessment of Migration of Contaminants from the Coal-Mining Waste Dumps, Extended Abstracts, abstract id: 317,,XXXVIII IAH Congress, Groundwater Quality Sustainability, Krakow, 12-17 September 2010, Eds: Kania J., Kmiecik, E., Zuber A.

Goodman, E., E. \& SHI G., H. (1985). Block Theory and its Application to Rock Engineering. Englewood Clifs, N.J., Prentice-Hall, Inc.

Halliburton (1991). Log Interpretation Charts, Halliburton Logging Services, Inc., Houston, Texas, USA.

Hearst, J., R., Nelson, P., H. \& Paillet, F., L. (2000). Well Logging for Physical Properties. A Handbook for Geophysicists, Geologists and Engineers. Wiley \& Sons, ISBN 0-47196305-4, Chichester, England.

Jarzyna, J., Bała, M. \& Cichy, A. (2010). Elastic parameters of rocks from well logging in Near Surface Sediments. Acta Geophysica, Vol. 58, No 1, pp. 34-48.

Jarzyna, J., Puskarczyk, E., Bała, M. \& Papiernik, B. (2009). Variability of the Rotliegend Sandstones in the Polish Part of the Southern Permian Basin - Permeability and Porosity Relationships. Annales Societatis Geologorum Poloniae, Vol. 79, pp. 13-26.

Jol , H., M. (2009). Ground Penetrating Radar Theory and Applications, Elsevier, ISBN 978-0-44453348-7, Amsterdam.

Kobranova, V., N. (1986). (Eng. Translation 1989). Petrophysics. MIR Publish. Moscow, Springer-Verlag, ISBN 3-540-51524-0, Berlin, Heidelberg, New York.

Kotlarczyk, J. \& Ratajczak, T. (2002). Carpathian ochre from Czerwonki Hermanowskie near Tyczyn, Mineral and Energy Economy Research Institute, ISBN 83-89174-60-X, Krakow (in Polish).

Liu Y.X., (2007). Evaluation and extraction of weak gravity and magnetic anomalies. Applied Geophysics, Vol. 4, No.4, pp. 288-293.

Madej J., Jakiel K. \& Porzucek S. (2001). Microgravimetric assesment of possible surface deformations in some post-mining areas. Mineral Deposits at the Beginning of the 21st Century, Proc. of the Joint Sixth Biennial SGA-SEG Meeting, Krakow, 26-29 August 2001, A.A. Balkema Publishers, pp.1035-1038.

Mange, C. \& Kochonov M. (1997). Anisotropic Material with Interacting Arbitrarily Oriented Cracks. Stress Intensity Factor and Crack-Microcrack Interactions. International Journal of Fracture, Vol. 65, pp. 115-141.

Marcak, H. \& Tomecka-Suchoń S. (2010). Properties of Georadar Signals Used for an Estimation of the Mineralization of the Soil Waters, Archives of Mining Sciences, Vol. 55, No. 3, pp. 469-487.

Nguyen, van, G., Ziętek, J., Nguyen, Ba, D., Karczewski, J. \& Gołębiowski, T. (2005). Study of Geological Sedimentary Structures of the Mekong River Banks by Ground Penetrating Radar: Forecasting Avulsion-Prone Zones, Acta Geophysica Polonica, Vol. 53, No. 2, pp. 167-181, ISSN 1895-6572. 
Rosowiecka, O. \& Nawrocki, J. (2010). Assesment of Soils Pollution Extent in Surroundings of Ironworks Based on Magnetic Analysis. Studia Geophysica et Geodaetica, Vol. 54, No.1, (December 2009), pp.185-194, ISSN 0039-3169.

Schön, J., K. (2004). Physical Properties of Rocks. Fundamentals and Principles of Petrophysics. Handbook of Geophysical Exploration, Seismic Exploration, Helbig K. and Treitel S., (Eds), v. 18, Elsevier, ISBN 0-08-044346-X, Oxford, UK.

Tiab, D., \& Donaldson, E.,C. (2004). Petrophysics. Theory and Practice of Measuring Reservoir Rock and Fluid Transport Properties. (sec. ed.), Elsevier, ISBN 0-7506-7711-2, Amsterdam, Boston, Heidelberg, London, New York, Oxford, Paris, San Diego, San Francisco, Singapore, Sidney, Tokyo, Gulf Professional Publishing.

Upadhyay, S., K. (2004). Seismic Reflection Processing, Springer, Berlin.

Wojas, A. (2009). Magnetic Susceptibility of Soils, Including Iron Oxides of Anthropogenic and Natural Origin - Measurements Using the Bartington Instrument, Proceedings of InterTech - II International Interdisciplinary Technical Conference of Young Scientists, ISBN 978-83-926896-1-4, Poznań, Poland, May 2009.

Wójcicki, A. (1993). Approximation of the Gravity Attraction Caused by the Terrain Relief Forms Using a Polyhedron Method. Acta Geophysica Polonica, Vol. 41, No. 3, pp.124. 


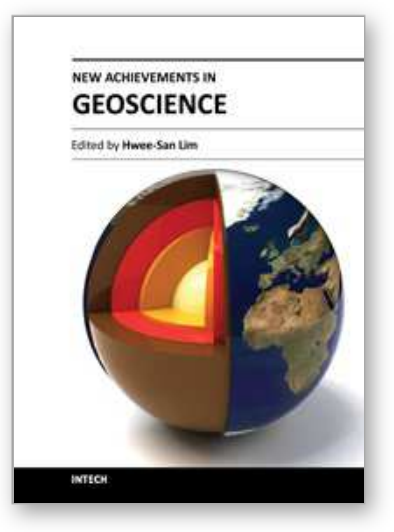

\author{
New Achievements in Geoscience \\ Edited by Dr. Hwee-San Lim
}

ISBN 978-953-51-0263-2

Hard cover, 212 pages

Publisher InTech

Published online 23, March, 2012

Published in print edition March, 2012

New Achievements in Geoscience is a comprehensive, up-to-date resource for academic researchers in geophysics, environmental science, earth science, natural resource managements and their related support fields. This book attempts to highlight issues dealing with geophysical and earth sciences. It describes the research carried out by world-class scientists in the fields of geoscience. The content of the book includes selected chapters covering seismic interpretation, potential field data interpretation and also several chapters on earth science.

\title{
How to reference
}

In order to correctly reference this scholarly work, feel free to copy and paste the following:

Jadwiga A. Jarzyna, Jerzy Dec, Jerzy Karczewski, Sławomir Porzucek, Sylwia Tomecka-Suchoń, Anna Wojas and Jerzy Ziętek (2012). Geophysics in Near-Surface Investigations, New Achievements in Geoscience, Dr. Hwee-San Lim (Ed.), ISBN: 978-953-51-0263-2, InTech, Available from:

http://www.intechopen.com/books/new-achievements-in-geoscience/geophysics-in-near-surface-investigations

\section{INTECH}

open science | open minds

\section{InTech Europe}

University Campus STeP Ri

Slavka Krautzeka 83/A

51000 Rijeka, Croatia

Phone: +385 (51) 770447

Fax: +385 (51) 686166

www.intechopen.com

\section{InTech China}

Unit 405, Office Block, Hotel Equatorial Shanghai

No.65, Yan An Road (West), Shanghai, 200040, China

中国上海市延安西路65号上海国际贵都大饭店办公楼 405 单元

Phone: +86-21-62489820

Fax: +86-21-62489821 
(C) 2012 The Author(s). Licensee IntechOpen. This is an open access article distributed under the terms of the Creative Commons Attribution 3.0 License, which permits unrestricted use, distribution, and reproduction in any medium, provided the original work is properly cited. 